UNIVERSIDADE DE SÃO PAULO

ESCOLA DE ENFERMAGEM

MARIA REGINA CAMARGO FERRAZ SOUZA

\title{
PERFIL DAS PESSOAS EM SITUAÇÃO DE RUA COM PROBLEMAS DE SAÚDE MENTAL DECORRENTES DO USO DE ÁLCOOL E OUTRAS DROGAS: REVISÃO DE ESCOPO
}

SÃO PAULO

2020 
UNIVERSIDADE DE SÃO PAULO

ESCOLA DE ENFERMAGEM

MARIA REGINA CAMARGO FERRAZ SOUZA

\section{PERFIL DAS PESSOAS EM SITUAÇÃO DE RUA COM PROBLEMAS DE SAÚDE MENTAL DECORRENTES DO USO DE ÁLCOOL E OUTRAS DROGAS: REVISÃO DE ESCOPO}

Dissertação apresentada ao Programa de PósGraduação em Enfermagem (PPGE) da Escola de Enfermagem da Universidade de São Paulo para obtenção do título de Mestre em Cuidado em Saúde

Área de concentração: Cuidado em Saúde

Orientadora: Prof. ${ }^{a}$ Dra ${ }^{\text {a }}$. Márcia Aparecida

Ferreira de Oliveira

\section{SÃO PAULO}


AUTORIZO A REPRODUÇÃO E DIVULGAÇÃO TOTAL OU PARCIAL DESTE TRABALHO, POR QUALQUER MEIO CONVENCIONAL OU ELETRÔNICO, PARA FINS DE ESTUDO E PESQUISA, DESDE QUE CITADA A FONTE.

Assinatura:

Data:

\section{Catalogação-na-publicação (CIP)}

Biblioteca Wanda de Aguiar Horta

\section{Escola de Enfermagem da Universidade de São Paulo}

Souza, Maria Regina Camargo Ferraz

Perfil das pessoas em situação de rua com problemas de saúde mental decorrentes do uso de álcool e outras drogas: revisão de escopo / Maria Regina Camargo Ferraz Souza. São Paulo, 2020. $95 \mathrm{p}$.

Dissertação (Mestrado) - Escola de Enfermagem da Universidade de São Paulo.

Orientador(a): Prof. ${ }^{a}$ Dr. ${ }^{\text {a }}$ Márcia Aparecida Ferreira de Oliveira Área de concentração: Cuidado em Saúde.

1. Pessoas em Situação de Rua. 2. Transtornos Relacionados ao Uso de Substâncias. 3. Drogas llícitas. 4. Enfermagem. 5. Saúde Mental. I. Título

Ficha catalográfica automatizada.

Bibliotecária responsável: Fabiana Gulin Longhi (CRB-8: 7257) 
Nome: Maria Regina Camargo Ferraz Souza

Título: Perfil das pessoas em situação de rua com problemas de saúde mental decorrentes do uso de álcool e outras drogas: revisão de escopo

Dissertação apresentada à Escola de Enfermagem da Universidade de São Paulo para obtenção do título de Mestre em Ciências da Saúde.

Aprovado em

BANCA EXAMINADORA

Prof. Dr. Instituição:

Julgamento: Assinatura:

Prof. Dr. Instituição:

Julgamento: Assinatura:

Prof. Dr. Instituição:

Julgamento: Assinatura: 


\section{DEDICATÓRIA}

Ao Lucas, meu esposo, companheiro de jornada e maior incentivador.

A meus filhos Lucas Maximus, Diana e Joaquim:

tudo é por vocês, tudo é pra vocês. 


\section{AGRADECIMENTOS}

A Profa ${ }^{a}$. Dra . Márcia Aparecida de Oliveira, que me acolheu e guiou durante todo o processo do mestrado.

Aos Professores Dro Divane de Vargas, Drª. Heloísa Garcia Claro Fernandes e Dro Ivan Filipe Fernandes, pelas valiosas contribuições no Exame de Qualificação.

Ao GEAD, em especial Júlia Cerione, meu ombro amigo durante toda essa caminhada.

Ao meu pai Reginaldo, que por meio de seu trabalho e esforço possibilitou que esse sonho se concretizasse.

A minha mãe lara e minha avó Izaura, por todo carinho e zelo.

A Ana Júlia, minha irmã querida, que me incentivou e esteve ao meu lado quando mais precisei, principalmente no cuidado com o Maximus e a Di.

A Amós e Patrícia, meus sogros, pelo incentivo, amor e cuidado que tiveram em especial - com o Lucas Maximus, durante todo o processo.

Aos amigos Dro Eric Barione, Luiz Otávio e ao casal Elizabeth e Moacyr Húngaro, pelo incentivo e contribuição pessoal.

À CAPES e CNPq pela concessão da bolsa de mestrado e pelo apoio financeiro para a realização desta pesquisa. 
"Nosso sistema funciona de um jeito que Os mais sofridos são sempre excluídos No poder, abandonados Passou no jornal eu vi Esgoto aberto, ar contaminado Cheiro de matar soldado Buscando sobrevivência Morando ao lado no bairro da penitência Foi condenado, viver é sua sentença" Sofridos e excluídos, CPM22 
Souza, MRCF. Perfil das pessoas em situação de rua com problemas de saúde mental decorrentes do uso de álcool e outras drogas: revisão de escopo [Dissertação]. São Paulo (SP), Brasil: Escola de Enfermagem, Universidade de São Paulo; 2020. 95 p.

\section{RESUMO}

O índice de pessoas em situação de rua com problemas de saúde mental decorrentes do uso de álcool e outras drogas têm crescido significativamente no mundo todo. A cidade de São Paulo pode ser considerada reflexo disto, visto que dados publicados pela Secretaria Estadual de Desenvolvimento Social apontam o aumento de $160 \%$ do fluxo de usuários na região da central da cidade, entre os anos de 2016 e 2107. Sendo assim, o presente estudo busca traçar o perfil desta população através da síntese da literatura já publicada na área. Objetivos: Analisar a produção científica sobre o perfil das pessoas em situação de rua que fazem uso de álcool e outras drogas, publicada a partir de 2009. Método: Trata-se de uma revisão de escopo (Scoping Review), em que os resultados foram obtidos por meio da busca de artigos publicados nas bases de dados LILACS/BVS, PUBMED e Google Acadêmico. A escolha de referências seguiu os seguintes critérios de elegibilidade: estudos completos, disponíveis online, publicados a partir de 2009, nos idiomas português, inglês e espanhol. Resultados: Foram analisados 9 artigos, sendo 7 nacionais e 2 internacionais e, submetidos a aplicação de um instrumento de extração de dados. Os resultados das análises apontam que a população em situação de rua com problemas mentais pelo uso de álcool e outras drogas é majoritariamente composta por homens, sendo a cor/raça parda predominante e com nível de ensino fundamental incompleto. Causas mais frequentes apontadas como motivo para a permanência na rua foram uso de drogas e desavenças familiares. Em relação ao consumo de drogas, álcool, tabaco e crack se mostraram como substâncias mais utilizadas. Conclusão: Por meio da análise proposta pelo presente estudo foi possível observar dados importantes sobre das características da população em situação de rua em uso de álcool e outras drogas. Conclui-se que estudos de caracterização são imprescindíveis para melhoria da qualidade de vida 
de pessoas em vulnerabilidades, uma vez que possibilitam recursos para a criação de estratégias efetivas na garantia de direitos e no combate adversidades sociais e de saúde enfrentadas.

Descritores: Pessoas em Situação de Rua, Transtornos Relacionados ao Uso de Substâncias, Drogas llícitas, Enfermagem, Saúde Mental 
Souza, MRCF. Profile of homeless people with mental health issues resulting from the use of alcohol and other drugs: scope review [Dissertation] São Paulo (SP), Brazil. Escola de Enfermagem, Universidade de São Paulo, 2020. 95 p.

\section{ABSTRACT}

The number of homeless people with mental health issues due to the use of alcohol and other drugs has grown significantly in the world. São Paulo city can be considered a reflection of this growth. Data published by the State Social Development Secretary show a $160 \%$ raise in the flow of drug users in the central part of the city, between the years 2016 and 2017. Therefore, this study seeks to outline the profile of this population through a synthesis of the literature already published in this area. Objective: To analyze the scientific production regarding homeless people who use alcohol and other drugs, published since 2009. Method: Scoping Review, in which the results were obtained by searching articles published in the LILACS/BVS, PUBMED and Google Academic databases. The choice of references followed the next eligibility criteria: complete studies, online availability, published since 2009, in Portuguese, English and Spanish. Results: 9 articles were analyzed, 7 are national (Brazil) and 2 international, and submitted to the application of a data extraction instrument. The results of the analyzes point that the homeless population with mental health issues due to the use of alcohol and other drugs is mostly composed of men, with brown being the predominant color/race, with no elementary school degree. Most frequent causes found as reason for staying on the streets were drug use and family disagreements. Regarding drug consumption, alcohol, tobacco, and crack were found to be the most used substances. Conclusion: Through the analysis proposed by this study it was possible to observe important data regarding the characteristics of the homeless population using alcohol and other drugs. It is concluded that characterization studies are essential to improve the life quality of people in a vulnerable situation, once these studies provide resources for the creation of effective strategies in the guaranteeing the rights and fighting social and health adversities that these people face. 
Key words: Homeless People, Substance-Related Disorders, Street Drugs, Nursing, Mental Health 


\section{LISTA DE SIGLAS}

CAPS Centros de Atenção Psicossocial

SRT Serviços Residenciais Terapêuticos

CECCO Centros de Convivências

PVC Programa de Volta para Casa

CAPS AD Centros de Atenção Psicossocial - Álcool e Drogas

CRATOD Centro de Referência de Álcool, Tabaco e Outras Drogas

PNPSR Política Nacional para População em Situação de Rua

SUS Sistema Único de Saúde

SUAS Sistema Único de Assistência Social

PL Projeto de Lei

CONFEN Conselho Federal de Entorpecentes

SISNAD Sistema Nacional Antidrogas

SENAD Secretaria Nacional Antidrogas

CONAD Conselho Nacional Antidrogas

PENAD Política Nacional Antidrogas

PCC População/ Conceito/Contexto

JBI The Joanna Briggs Institute

GEAD Grupo de Estudos de Álcool e Drogas

ARYS At-risk Youth Study

SPA Substância Psicoativa

SP São Paulo 
UBS Unidade Básica de Saúde

ESF Estratégia Saúde da Família

UPA Unidade de Pronto Atendimento

RJ Rio de Janeiro 


\section{LISTA DE QUADROS E FIGURAS}

Quadro 1 - $\quad$ Grupos comumente encontrados em situação de rua e suas características definidoras

Quadro 2 - Descrição da estratégia PCC

Quadro 3 - $\quad$ Resumo das bases de dados selecionadas e respectivas palavras-chave e descritores estabelecidos, conforme o PCC

Quadro 4 Estratégia de busca detalhada

Quadro 5 Artigos incluídos após a leitura dos títulos e resumos

Quadro 6 Artigos excluídos após leitura completa

Quadro 7 Artigos eleitos submetidos a análise

Figura 1 Pessoas que ficam na rua, que estão na rua e que são da rua: características definidoras

Figura 2 - $\quad$ Processo de seleção de estudos 


\section{SUMÁRIO}

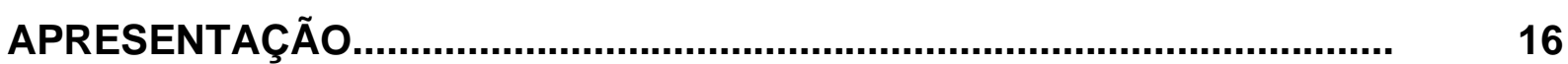

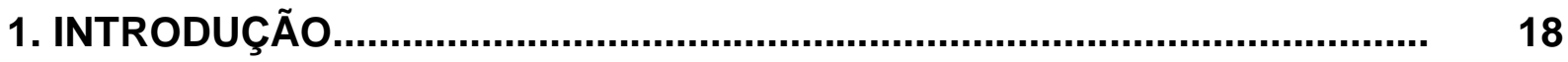

\section{APORTE TEÓRICO}

2.1. A Situação de Rua.................................................................... 21

2.2. Política Nacional para População em Situação de Rua................ $\quad 24$

2.3. Histórico da assistência a pessoas com problemas de saúde $\quad 25$ mental decorrentes do uso de álcool e outras drogas no Brasil

\section{OBJETIVOS}

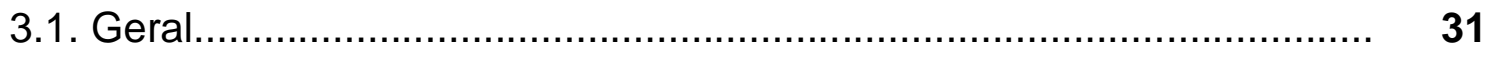

3.2. Específicos....................................................................... $\quad 31$

4. MÉTODO

4.1. Etapas da pesquisa................................................................ $\quad 33$

4.2. Estratégias de busca............................................................... $\quad 35$

4.3. Critérios de inclusão e exclusão........................................................ $\quad 36$

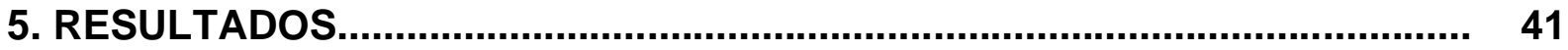

5.1. Artigos selecionados/ elegíveis.................................................... $\quad \mathbf{3 8}$

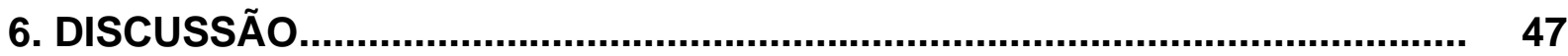

7. CONSIDERAÇÕES FINAIS................................................................. 58

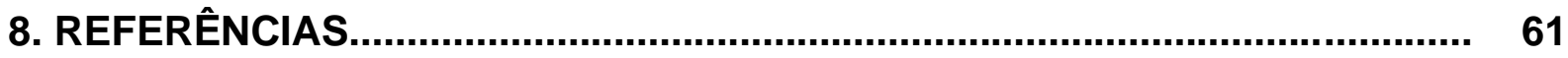

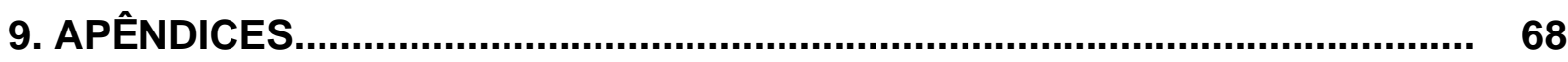

Apêndice A - Instrumento de extração de dados........................................ 68

Apêndice B - Resultados da extração de dados............................................ 69

Apêndice C - Protocolo da revisão de escopo............................................. 87 


\section{APRESENTAÇÃO}

Meu interesse pelo cuidado em Saúde Mental e, sobretudo na temática de álcool e outras drogas, deu-se logo nos primeiros anos do meu curso de graduação em Enfermagem, o que desde lá direcionou todo meu percurso profissional para essa área.

Durante o meu percurso assistencial, fui entendendo e identificando que o trabalho na saúde mental é caracterizado por diferentes momentos e concepções, influenciado, sobretudo, pelo entendimento social e cultural sobre o uso de álcool e outras drogas.

O modelo assistencial em saúde mental é resultado de políticas sociais predominantes em um determinado momento histórico-político. Entende-se que Políticas Sociais é um conjunto de intenções e gestos que traduzem os interesses do Estado para assegurar a reprodução das relações sociais com base na divisão da sociedade em classes sociais ${ }^{1}$.

Por um longo período a sociedade foi marcada pela exclusão de grupos sociais, sobretudo as pessoas com problemas de saúde mental decorrentes do uso de álcool e outras drogas, tendo como justificativa as normas estabelecidos pelos grupos sociais dominantes.

Dentro de todo esse panorama surgem assim as instituições psiquiátricas, conhecidos como manicômios, que por um longo período caracterizaram o modelo assistencial em saúde mental no Brasil e em outros países ao redor do mundo.

Em diversos países da Europa e nos Estados Unidos inicia-se um processo de mudança de paradigma na concepção do transtorno mental. Conhecidos como Movimentos de Reforma Psiquiátrica, propunham, sobretudo entre outros objetivos, a democratização das relações entre profissionais e pacientes e o deslocamento da assistência do manicômio para serviços na comunidade².

Em 2001 foi aprovada a Lei № 10.216 em 06 de abril de 2001, que dispõe sobre a proteção e os direitos das pessoas portadoras de transtornos mentais, redirecionando o modelo assistencial em saúde mental no Brasil Entre outros avanços, a lei oficializou o processo de implementação de políticas públicas em 
saúde mental direcionando a substituição progressiva dos leitos em hospitais psiquiátricos para uma rede chamada substitutiva ${ }^{3}$.

Conhecidos como serviços ou políticas substitutivas, os Centros de Atenção Psicossocial (CAPS), os Serviços Residenciais Terapêuticos (SRT), os Centros de Convivências (CECCO), os leitos em Hospitais Gerais, o Programa de Volta para Casa (PVC), entre outros; trabalham para a desinstitucionalização, reinserção e autonomia de portadores de transtornos mentais graves, assim como para a construção de um novo olhar e de um novo lugar social para essas pessoas ${ }^{4}$.

Em 2002, o Ministério da Saúde, lançou o Programa Nacional de Atenção Integral a Usuários de Álcool e Outras Drogas. Considerando que, no contexto dessa pesquisa, podemos supor que para a atuação dos profissionais de saúde em relação às pessoas com problemas de saúde mental decorrentes do uso de álcool e outras drogas e estão em situação de rua, o perfil possa ser um elemento importante a ser identificado, no intuito de se desenvolver boas práticas de cuidado.

Portanto, este estudo tem como foco pessoas em situação de rua com problemas de saúde mental decorrentes do uso de álcool e outras drogas, identificando o perfil desta população, propondo-se a realização de uma revisão sistemática de escopo no intuito de verificar o estado da arte em relação a essa temática. 


\section{INTRODUÇÃO}

Frequentemente, o uso de álcool e outras drogas estão presentes no cotidiano de quem mora na rua como forma de suportar a situação, seja a fim de minimizar a fome e o frio, ou como uma forma de socialização entre os membros dos grupos. Tal condição se apresenta, ora como um dos motivos primordiais da permanência da situação de rua; ora como consequência do ingresso no mundo da rua $^{5}$.

Tanto a situação de rua quando o uso de álcool e outras drogas por si estigmatiza e coloca pessoas que se encontram nestes grupos às margens da população. Por sua vez, estas condições associadas aumentam a dificuldade destas pessoas no acesso a serviços básicos, comuns ao restante da população.

Nos últimos anos tem se tornado perceptível o crescimento massivo da população em situação de rua com problemas de saúde mental decorrente do uso de álcool e outras drogas.

A exemplo disso, no município de São Paulo, o mais populoso do país, com 12,18 milhões de habitantes ${ }^{6}$, a concentração de pessoas em uso problemático álcool e drogas, majoritariamente no centro da cidade tem aumentado em proporções significativas.

Segundo levantamento da Secretaria Estadual de Desenvolvimento Social, entre abril de 2016 e maio de 2017 houve aumento de $160 \%$ do fluxo de pessoas com problemas de saúde mental decorrentes do uso de álcool e drogas ${ }^{7}$. Este aumento expressivo da população da Cracolândia e de ações de repressão ganharam então destaque na mídia, o que reacendeu debates sobre a estigmatização e a efetividade de políticas públicas voltadas as vulnerabilidades desta população devido ao uso problemático de substâncias psicoativas (SPAs).

Diante do questionamento apresentado, se faz necessário conhecer quem são essas pessoas em situação de vulnerabilidade. É preciso compreender suas características definidoras e traçar o perfil desta população para que as ações de 
saúde as alcance. Este passo é necessário para auxiliar na formulação de políticas públicas acessíveis e efetivas.

Ressalta-se que cuidado dos usuários de álcool e drogas no Brasil caminha junto com as mudanças instituídas no país a partir da Lei 10.2016/2001, uma vez que primeiras políticas públicas voltadas ao tratamento do uso abusivo de álcool e outras drogas começaram a ser discutidas e implementadas no início dos anos 2000.

A partir daí, em 2002, o Ministério da Saúde, por meio da Portaria no $816^{8}$, criou o Programa Nacional de Atenção Integral a Usuários de Álcool e Outras Drogas, que entre outras disposições, - como a articulação em rede e para a organização de fluxos assistenciais nas três esferas de governo - propos a criação dos primeiros Centros de Atenção Psicossocial - Álcool e Drogas (CAPS AD).

No mesmo ano, o Governo do Estado de São Paulo o instituiu o decreto no 46.860/2002, criando assim o Centro de Referência de Álcool, Tabaco e Outras Drogas - CRATOD, que posteriormente, através da Portaria 2.103/GM, foi habilitado entre os primeiros CAPS-AD do país ${ }^{9}$.

A criação e implantação do CRATOD foi um processo transformador na assistência ao tratamento de álcool e outras drogas oferecido pelo Estado, pois possibilitou o oferecimento de um serviço alinhado com as propostas da Reforma Psiquiátrica e mais acessível à sua população alvo, que até então era estigmatizada e excluída.

Em 2012, dez anos após sua criação, o CRATOD foi reformulado e a partir da Portaria no 130/2012, do Ministério da Saúde, o serviço passa a ser classificado como o CAPSAD III Qualificado e com o decreto estadual no 57.775/2012, passa a ter funcionamento ininterrupto. ${ }^{9}$

Assim, em 2013, houve um novo aporte de recursos financeiros e humanos para a Instituição. Esse aporte permitiu então o desenvolvimento de ações de cuidado mais próximas do território da Cracolândia e das pessoas com problemas mentais decorrentes do uso de drogas. 
Visando assim aperfeiçoamento e integração de suas ações de manejo da dependência química, através do decreto no 59.684/2013, foi instituído o Programa Estadual de Enfrentamento ao Crack - Programa Recomeço, que, vinculado ao CRATOD, tem por objetivo atender usuários de substâncias psicoativas especialmente o crack, e seus familiares ${ }^{10}$.

Em 2015, houve reestruturação do Programa Recomeço (Decreto no 61.664/2015), que passou a se denominar Programa Estadual de Políticas sobre Drogas - Programa Recomeço: uma vida sem drogas ${ }^{11}$. O Programa também passou a contar com a atuação coordenada das Secretarias da Educação, Saúde, Desenvolvimento Social, Segurança Pública e Justiça.

Até 2018, o serviço chegou a oferecer mais de 2.500 internações e 1.500 acolhimentos em comunidades terapêuticas. Dentro do seu CAPS-AD III (Centro de Atenção Psicossocial - Álcool e Drogas), realiza mais de 2.000 oficinas, que atendem 25.000 pessoas, além de projetos terapêuticos singulares e serviços odontológicos para mais de 1.300 pacientes, todos os anos 9 .

Mesmo com a implementação de serviços e ações como o CRATOD e Recomeço, dos Governos Estadual e Municipal de São Paulo, o acesso da população de rua ainda é algo que necessita ser discutido e ampliado.

Tendo em vista as dificuldades da população de rua que faz uso de álcool e outras drogas ao acesso a serviços essenciais, dentre outros problemas, o presente estudo busca responder, com base na literatura quem são estas pessoas e quais características definidoras trazem consigo. 


\section{APORTE TEÓRICO}

\subsection{A Situação de Rua}

Para compreender a pessoa em situação de rua se faz necessário entender o contexto em que está se encontra, ou seja, a rua.

Culturalmente, o conceito de rua como espaço está relacionado constantemente ao do espaço casa; ambos podem ser considerados espaços físicos que carregam preceitos sociais e comportamentais. Exemplificando, é possível considerar que alguns comportamentos só são aceitos na rua, enquanto outros somente em casa.

Enquanto por vezes a rua está ligada a um ambiente complexo, aberto, violento, a casa por sua vez é considerada um ambiente oposto, que frequentemente caracterizada como um lugar harmonioso, seguro e acolhedor.

Desta forma, pode-se considerar que "ser posto para fora de casa" é um ato violento, pois perdemos aquilo que supostamente esse espaço nos oferece de melhor, o aconchego e a proteção ${ }^{12}$.

Apesar de casa e rua se reproduzirem mutuamente como opostos e a rua ainda ser considerada por muitos local inóspito, a mesma pode assumir por vezes o papel da casa: ora caracterizada como lugar de passagem (onde o sujeito permanece por um certo período, até encontrar outra casa ou abrigo), ora sendo local de vivência contínua.

Tendo em vista a heterogeneidade dos sujeitos que vivem em situação de rua' é possível categorizar os grupos comumente encontrados dentro da população de rua, conforme estudo dos autores Snow e Anderson (1998 apud Abreu, 2013) ${ }^{13}$. Abaixo, segue quadro 1, baseada na divisão de grupos apresentada pelos autores, com base em suas características definidoras. 


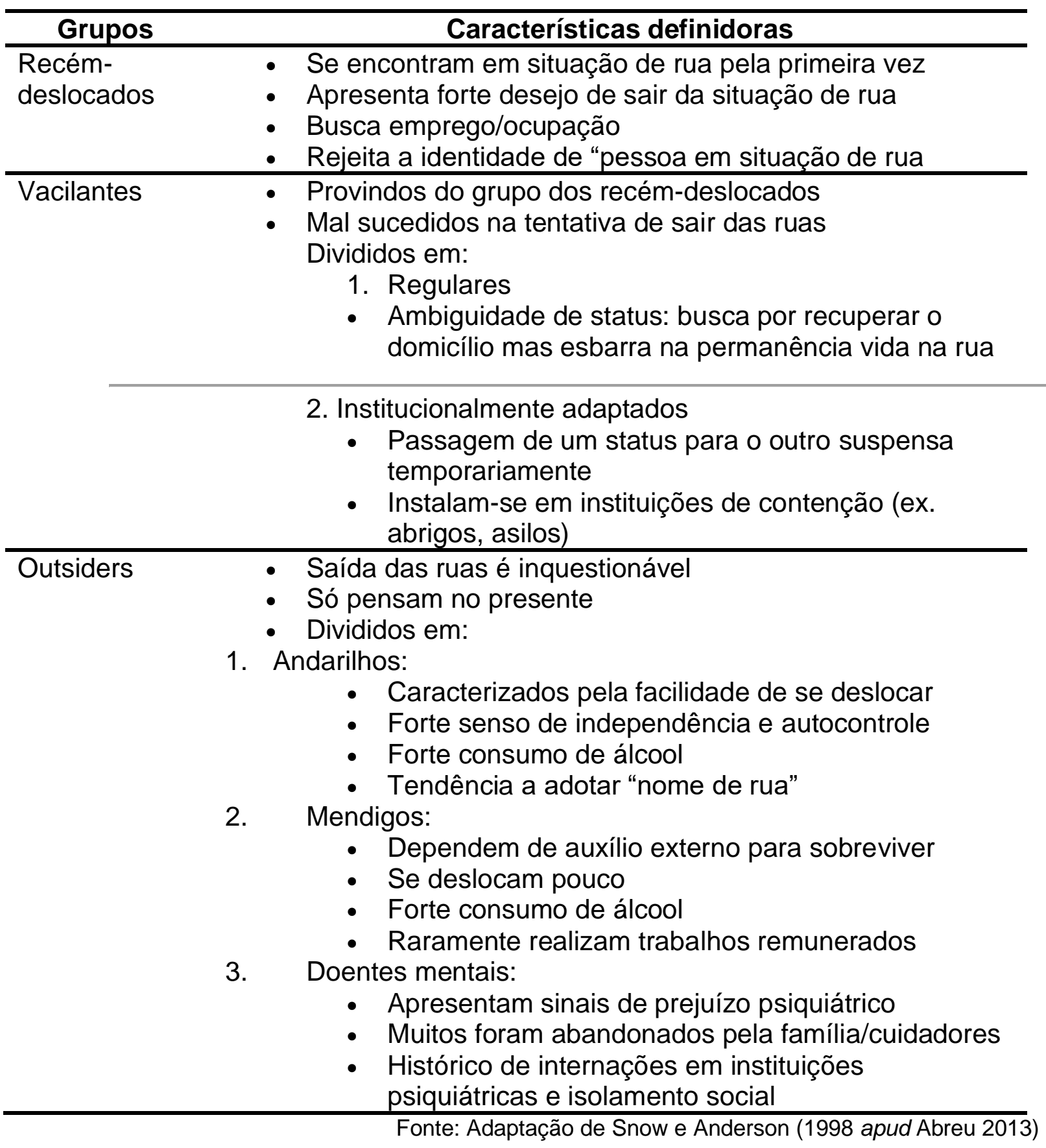

Quadro 1 - Grupos comumente encontrados em situação de rua e suas características definidoras. São Paulo, 2020

Buscando uma categorização menos rígida do que a apresentada por Snow e Anderson, outros autores em seus respectivos trabalhos, como Brognoli ${ }^{14}$ e Prates, Prates e Machado ${ }^{15}$ também contribuíram para a construção da identidade das pessoas em situação de rua. 
Apresentando um conceito parecido com o dos outsiders/andarilhos, Brognoli $(1996)^{14}$ descreve os "trecheiros".

"Estes, assim como os andarilhos, são vistos como pessoas que exibem comportamento migratório acentuado. Transitam de um local para o outro, sem permanecer por muito tempo em determinado local. Estão sempre no "trecho" entre um ponto e outro e não costumam parar [...] Em determinadas situações, os trecheiros podem até pedir auxílio (seja um prato de comida ou dinheiro), mas geralmente garante sua sobrevivência através da realização de trabalhos braçais."

Além dos trecheiros, o autor descreve os "pardais". As pessoas em situação de rua pertencentes a este grupo recebem tal nome em alusão ao pássaro pardal, pois "nunca se afastam muito do ninho". Em sua maioria, se estabelecem em lugares fixos, de fácil acesso. Também demonstram apego ao território em que vivem. Sua sobrevivência é basicamente oriunda do auxílio de outras pessoas. ${ }^{8}$

Já Prates, Prates e Machado ${ }^{15}$ argumentam sobre o uso de expressões como andarilhos e trecheiros, pois estariam mais ligadas ao ato de se locomover do que às pessoas em situação de rua.

Também podemos dividir a população em situação de rua, de forma simplificada, em três grupos, conforme o estudo de Vieira, Bezerra e Rosa ${ }^{16}$. As informações sobre os grupos e suas características estão dispostas na figura 1.

\section{Figura 1 - Pessoas que ficam na rua, que estão na rua e que são da rua: características definidoras.}
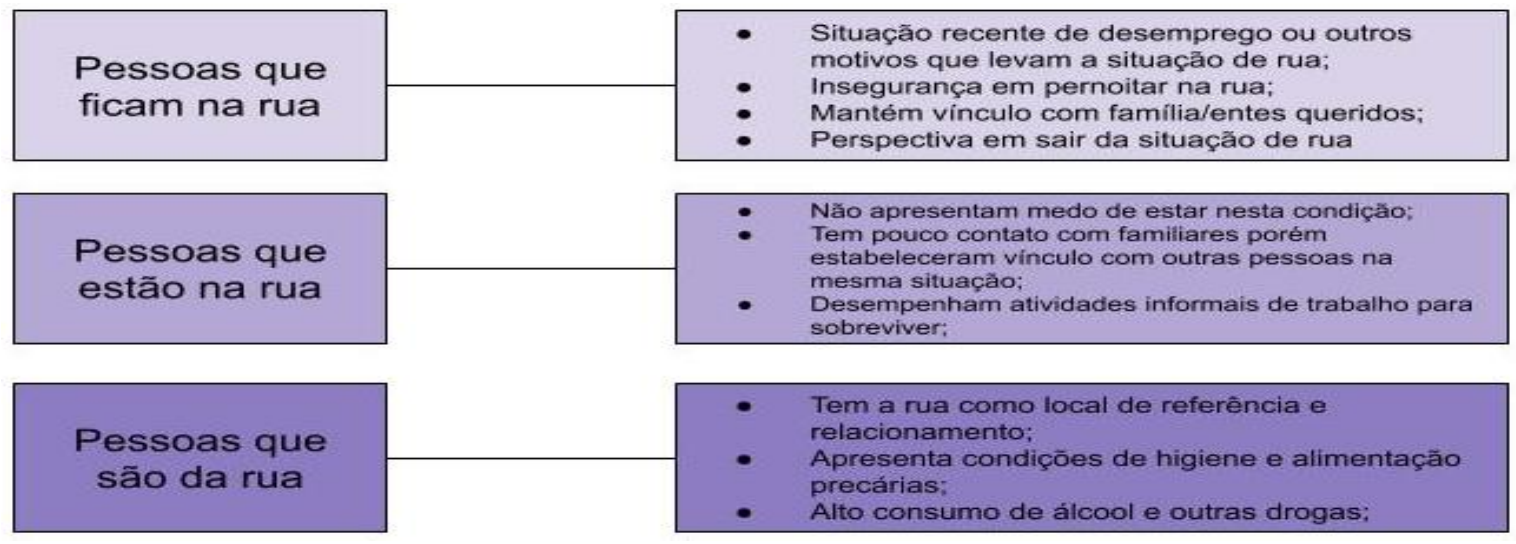

Fonte: Adaptado de Vieira (1992) 
Esta classificação nos permite identificar quais grandes grupos encontramos quando se trata das pessoas em situação de rua, principalmente clarifica as diferentes faces da população de rua: existem pessoas que ficam na rua, pessoas que estão na rua e pessoas que são da rua. Cada grupo possui características próprias que os divergem entre si.

Sendo assim, este estudo tem como população de interesse as pessoas que são da rua, dentro de suas singularidades.

\subsection{Política Nacional para População em Situação de Rua}

A Política Nacional para População em Situação de Rua (PNPSR) foi instituída pelo Governo Federal, em 23 de dezembro de 2009, a partir do decreto nº 7.053. ${ }^{17}$

Dentre outras disposições, a PNPSR define a população em situação de rua o grupo populacional heterogêneo, caracterizado pela pobreza extrema, quebra de vínculos familiares ou fragilização dos mesmos, além é claro, da carência de moradia convencional, levando a utilização de logradouros públicos como espaço de moradia e de sustento, sendo de forma temporária ou permanente. A utilização de unidades de acolhimento e albergues para pernoite temporário ou como moradia provisória também são características presentes da população em situação de rua.

A PNPSR também faz alusão aos princípios de equidade e igualdade, já previstos pelo Sistema Único de Saúde (SUS).

O acesso da população em situação de rua aos serviços e programas que integram as políticas públicas de saúde e a capacitação de pessoal no cuidado a este público são alguns dos objetivos destacados dentro da PNPSR, além da articulação entre o Sistema Único de Assistência Social (SUAS) e SUS.

Desta forma, é possível constatar que tratando-se da população em situação de rua, é imprescindível a associação entre a esfera social e a esfera de saúde. 


\subsection{Histórico da assistência a pessoas com problemas de saúde mental decorrentes do uso de álcool e outras drogas}

Para descrever a assistência a usuários de álcool e outras drogas no Brasil, é preciso retornar aos primórdios da assistência a saúde mental.

Historicamente, pessoas com doença mental eram mantidas trancafiadas, acorrentadas e em isolamento pela sociedade, pois eram tidas como extremamente agressivas e perigosas, influenciadas por espíritos malignos.

Até o século XVIII, o cuidado era apenas custodial (cuidados físicos, proteção) e havia poucos tratamentos disponíveis. ${ }^{18}$ O cuidado "moral" ou mais humanitário surgiu a partir dos princípios de Philippe Pinel, médico psiquiatra que provocou uma revolução na assistência aos doentes mentais e a assistência então deixou de ser custodial e passa a ser norteada de ser norteada por vigilância, restrição e contenção.

Inspirado pelo modelo alienista de Pinel, em 1852 foi inaugurado no Brasil, o Hospício Dom Pedro II, na cidade do Rio de Janeiro, e renomeado posteriormente de Hospício Nacional de Alienados. ${ }^{19} \mathrm{O}$ Brasil tornou-se assim o primeiro país da América Latina a fundar um grande manicômio.

A partir de então, vários asilos e manicômios foram construídos no país, dispensado aos doentes mentais um tratamento extremamente restrito ao interior dos grandes hospícios, através de internações prolongadas e manutenção da segregação social.

No início do século XX, com Sigmund Freud surge à visão do homem como um todo (físico-mente), iniciando uma transformação na assistência psiquiátrica, além do cuidado físico.

Por outro lado, a assistência de enfermagem continuou centrada na vigilância, restrição, assistência nos tratamentos até que, em 1952, Hildegard Peplau preconiza o relacionamento terapêutico enfermeira-paciente como instrumento básico da assistência de enfermagem psiquiátrica. 
Inicia-se então nesta uma grande transformação da assistência de enfermagem: anteriormente voltada e limitada aos cuidados físicos (higiene, limpeza), vigilância e contenção, passa a se centrar nas relações interpessoais.

A participação efetiva da equipe de enfermagem na assistência global ao paciente passa a ser conhecida e cobrada tanto em nível hospitalar como extrahospitalar. ${ }^{18}$

Influenciado pelo movimento da reforma psiquiátrica, a partir de 1970 o modelo de assistência psiquiátrica brasileira passou por reformulações, incluindo a criação de novos dispositivos de tratamento de base comunitária (como os Centros de Atenção Psicossocial) e mudanças na terapêutica e no modo de conceber e tratar a pessoa com transtorno mental.

As discussões sobre substituição do modelo assistencial - até então praticado no país -, chegaram ao Congresso Nacional, no final da década de 1980, por meio do Projeto de Lei (PL) apresentado pelo Deputado Paulo Delgado, que propunha além da regulamentação dos direitos das pessoas com transtornos mentais, a extinção progressiva dos manicômios. Após 12 anos de tramitação, foi promulgada a Lei $10.216 / 2001^{3}$, considerada um importante marco para a assistência psiquiátrica.

Em 2003, é iniciada a mudança do modelo assistencial no enfrentamento de adições, por meio da instituição da Política de Atenção Integral aos Usuários de Álcool e Outras Drogas, implementada pelo Ministério da Saúde ${ }^{20}$.

O combate do uso abusivo de álcool e outras drogas tardaram a ser responsabilidade do Sistema Único de Saúde (SUS). Por muitos anos, teve como protagonistas das ações interventivas órgãos ligados á Segurança Pública e Justiça.

A exemplo disto, no início do século $X X$, foi criado pelo governo brasileiro ações de caráter jurídico-institucionais com a finalidade de controlar o comércio de drogas e, preservar assim, a saúde pública do país.

Destaca-se também que na época, o álcool - droga moralmente aceita pela sociedade -, não era o foco do governo. Isso motivou o surgimento de sociedades e 
associações de caráter privado no engajamento do combate ao alcoolismo, através de ações fortemente higienistas e moralistas.

O aparato jurídico-institucional, como citado anteriormente, era focado no combate as drogas ilícitas e, previa penas onde os usuários eram excluídos do convívio social, através de reclusão em prisões, sanatórios e posteriormente, na década de 70, internações em hospitais psiquiátricos e a finalidade era salvar, recuperar, tratar e punir.

Em 1971, a lei 5.726 trouxe novas interpretações para o abuso de substâncias, tornando a psiquiatria aliada no controle e repressão do uso de drogas no país. Posteriormente, esta lei foi modificada pela lei $6.368 / 76$, que reafirmou a inserção do modelo médico-psiquiátrico, e favoreceram o surgimento dos primeiros centros de tratamentos de adições no país.

A lei 6.368/76 também favoreceu a criação do Conselho Federal de Entorpecentes (Confen). O Confen foi criado e regulamentado na década de 1980, sendo composto por integrantes de vários ministérios (como Justiça, Saúde, Assistência Social, entre outros) e inicialmente, tinha como foco a abordagem apenas as drogas ilícitas, o que ao longo da década foi sendo transformado, e o órgão passou também, a abordar questões voltadas às drogas lícitas, como álcool21.

Com a redemocratização do Brasil, na década de 1990, o Confen passou a atuar da repressão ao uso e tráfico de drogas, ao incentivo do surgimento de práticas de prevenção, tratamento e pesquisa. Suas propostas de ampliação de campo de atuação foram documentadas em 1988 e 1996, respectivamente.

O documento de 1988 tinha como proposta a criação dos centros de referência em prevenção e tratamento ao uso abusivo de drogas - lícitas e ilícitas, e preconizava que o Sistema Nacional de Saúde atendesse esta população de maneira eficaz.

Já o documento de 1996 propunha o desenvolvimento harmonioso entre ações preventivas, repressivas e de tratamento, além de alertar sobre o aumento da disseminação do vírus do HIV entre usuários de drogas injetáveis. Também propôs o 
estabelecimento de critérios e normas para o funcionamento de instituições de tratamento e implementação de serviços específicos para a assistência aos dependentes químicos.

Sendo assim a criação dos centros de referências, tratamento, prevenção e pesquisa (iniciados na década de 1980) foram reconhecidos pelo Confen. Grande parcela destes centros iniciou-se em universidades, contribuindo para a produção técnico científica relacionada ao tema.

Na década de 1990, a postura tomada pelo Confen sobre o desenvolvimento de ações de redução de danos, por meio de ações como troca de seringas e distribuição de insumos para o uso seguro de drogas foi considerada por alguns órgãos ligados ao governo e igreja católica como um "incentivo ao uso de drogas".

O princípio da redução de danos se sustenta no pragmatismo de que o consumo de drogas não pode ser suprimido pela sociedade, mas é possível traçar estratégias para reduzir os danos a ele relacionados ${ }^{22}$.

Mesmo em meio à polêmica gerada, os projetos de redução de danos proporcionaram visibilidade à realidade da atenção ao usuário de drogas no setor público de saúde.

Nesta época houve o crescimento das comunidades terapêuticas, majoritariamente motivado pela iniciativa de famílias e voluntários. O Confen contribuiu para que as normas e requisitos para o funcionamento destes serviços fossem criadas.

Em junho de 1998, por decreto do presidente da época, Fernando Henrique Cardoso, o Confen foi extinto, e posteriormente, instituídos o Sistema Nacional Antidrogas (SISNAD) - a fim de reportar atividades de repressão e prevenção -, composto pela Secretaria Nacional Antidrogas (SENAD) e Conselho Nacional Antidrogas (CONAD).

Ainda em 1998, aconteceu o 1ำ Fórum Antidrogas, onde foi criada a Política Nacional Antidrogas (PNAD). Em 2001, ocorreu o 2ํFórum, onde o projeto político 
foi apresentado à sociedade. Importante salientar que o evento ocorreu concomitante a Conferência Nacional de Saúde Mental ${ }^{21}$.

O compromisso de enfrentar os problemas associados ao consumo de álcool e outras drogas consolidou-se apenas em 2003, no início da gestão do Presidente Luís Inácio Lula da Silva. No documento oficial foram definidos os marcos teóricopolíticos e as diretrizes para a atenção ao uso de substâncias (em consonância com os princípios do SUS, reforma psiquiátrica e a lógica ampliada de redução de danos).

Em 2006, com a criação da Lei 11.343, as atividades de repressão ao tráfico ganharam definição criminal e aumento de penalidades, além da distinção de usuários e dependentes de drogas, abordando de forma mais expressiva atividades de prevenção ao uso indevido, atenção e reinserção social.

É fato que prática da assistência a usuários de álcool e drogas no país transitou por muito como problema relacionado ao aparato jurídico, por vezes deixando a atenção à saúde desta população em segundo plano.

A criação de políticas públicas ao longo do século $X X$ foram essenciais para que a assistência aos usuários de álcool e outras drogas fosse transformada, tirando seu foco de ações repressivas e moralistas, transformando as práticas de atenção a esta população, buscando melhoria da qualidade de vida dos mesmos, através da redução de danos e reinserção social.

Por meio do decreto no 9.761 de abril de $2019^{23}$, o texto da PNAD foi alterado, tornando-a mais rígida. Dentre as alterações, destaca-se também a exclusão de ações voltadas para a redução de danos, facilitação de internações voluntárias e fortalecimento do modelo de Comunidade Terapêutica (instituições em grande parte vinculadas a organizações religiosas).

Por fim, mais uma alteração no campo das políticas públicas voltadas para a atenção de pessoas em uso de alcool e outras drogas foi aprovada, através da lei no 13.840 , sancionada em 05 de junho de $2019^{24}$. 
A principal alteração apresentada no texto da lei em evidencia diz respeito a alteração das modalidade de internação. A nova proposta exclui a modalidade de internação compulsório, tornando possível apenas internações voluntárias e involuntárias.

Desta forma, a internação involuntária é a modalidade onde se dá, sem o consentimento do dependente, a pedido de familiar ou do responsável legal ou, na absoluta falta deste, de servidor público da área de saúde, da assistência social ou dos órgãos públicos integrantes do Sisnad, com exceção de servidores da área de segurança pública, que constate a existência de motivos que justifiquem a medida. *

Esta reformulação das modalidades de internação ainda prevê que nos casos de internação involuntária o tratamento perdurará por até 90 dias, em leito hospitalar para desintoxicação, conforme necessidade observada pelo médico responsável pelo paciente ou quando a família e/ou responsáveis requerer interrupção do tratamento.

Tal alteração implica no retrocesso de políticas antimanicomiais, pois traz novamente a institucionalização de pessoas em uso de álcool e outras drogas, através do aparato de hospitalização. 


\section{OBJETIVOS}

\subsection{Geral}

Analisar a produção científica sobre o perfil das pessoas em situação de rua com problemas de saúde mental decorrentes do uso de álcool e outras drogas, publicada a partir do ano de 2009.

\subsection{Específicos}

- Elaborar uma revisão da produção de conhecimentos sobre o perfil das pessoas em situação de rua com problemas de saúde mental decorrentes do uso de álcool e outras drogas.

- Mapear e listar conceitos apresentadas pelos estudos referentes ao perfil das pessoas em situação de rua com problemas de saúde mental decorrentes do uso de álcool e outras drogas.

- Identificar as lacunas existentes em relação ao objeto do estudo. 


\section{MÉTODO}

O presente estudo trata-se de uma revisão de escopo (scoping review) que busca identificar o perfil de pessoas em situação de rua com problemas de saúde mental decorrentes do uso de álcool e outras drogas no Brasil e no mundo.

O modelo de Scoping Review tem como objetivo mapear os principais conceitos sustentadores dentro de uma área de pesquisa, elucidando as definições e limites teóricos de determinado tópico. Pode ser empregado anteriormente à realização de uma revisão sistemática. ${ }^{25}$

Diferentemente das revisões comuns de literatura, as revisões sistemáticas seguem critérios rigorosos para a busca e seleção de estudos. São levadas em consideração a avaliação da relevância e validade das pesquisas encontradas, e coleta, sintetiza e interpreta os dados oriundos das investigações.

As revisões sistemáticas são focadas em questões bem delineadas, onde é possível que os desenhos de estudo sejam identificados com antecedência. Também visam responder perguntas de âmbito relativamente estreito, referentes a estudos com qualidade avaliada. ${ }^{26}$

O scoping review possibilita uma maior abrangência de temas, incluindo diversos desenhos de estudo. O mapeamento em questão diz respeito a um processo de sumarização que permite chegar a uma evidência que transmita conhecimento amplo e profundo em determinado campo do saber. ${ }^{27}$

O conceito pode ser entendido como um mediador da natureza intelectual do pensar e do agir humano. É uma forma de organizar o conjunto de operação para lidar com um objeto ou uma situação. ${ }^{28}$

Há quatro razões ' comuns que justificam a utilização de um scoping review, de acordo com Arksey e O'malley²6:

1. Para examinar a extensão, o percurso e a natureza da investigação: embora não descreva os resultados da investigação em detalhes, esse tipo de revisão rápida é uma forma útil de mapeamento de campos de estudo nos quais é difícil visualizar a totalidade de materiais disponíveis. 
2. Para determinar o valor de uma revisão sistemática completa: nesses casos, um mapeamento preliminar da literatura pode ser realizado para identificar ou não, se uma revisão sistemática completa é possível (existe alguma literatura?) ou relevante (que revisões sistemáticas já foram realizadas? E os custos potenciais da condução de uma revisão sistemática completa.

3. Para resumir e divulgar os resultados de pesquisas: esse tipo de scoping review pode descrever em mais detalhes os resultados da pesquisa em áreas específicas de estudo, fornecendo, assim, um mecanismo de síntese e divulgação dos resultados da pesquisa a políticos, profissionais e consumidores, para os quais a falta de tempo ou de outra forma de recurso impossibilitariam acessar os resultados de outra maneira.

4. Para identificar as lacunas da investigação na literatura existente: esse tipo de scoping review faz do processo de divulgação um passo a mais para se obter conclusões sobre a literatura existente, considerando especialmente o estado de atividade da investigação em determinado campo. Especificamente, é designado a identificar em bases de dados, a existência e/ou ausência (lacuna) de pesquisas em uma dada temática. Ademais, o estudo também pode resumir e divulgar os resultados de trabalhos específicos, bem como identificar a relevância da revisão sistemática completa em áreas de investigação. No entanto, é importante notar que a identificação de lacunas na literatura por meio de um scoping review não necessariamente evidenciará os problemas de uma investigação de uma pesquisa ou a sua qualidade, ainda porque a avaliação da qualidade dos estudos não faz parte dos objetivos desse método.

Sendo assim, destacam-se os itens 1 e 4, que justificam a escolha desta metodologia para o presente estudo.

\subsection{Etapas da pesquisa}

Conforme as etapas previstas em um scoping review, seguiram-se os seguintes passos: (I) Identificar a questão norteadora da pesquisa, (II) Identificar os 
estudos relevantes; (III) Selecionar os estudos; (IV) mapear os dados; e (V) confrontar, resumir e relatar os resultados.

O presente estudo iniciou-se com o desenvolvimento de um protocolo com critérios de inclusão e exclusão que se reportaram para os objetivos e questão de revisão.

A estratégia "PCC", acrônimo referente a População, Conceito e Contexto ${ }^{18}$, foi utilizada para delimitação do objetivo. A descrição da estratégia utilizada pode ser observada no quadro 2.

\begin{tabular}{ll}
\hline PCC & Descritores \\
\hline População & $\begin{array}{l}\text { Pessoas com problemas de saúde mental decorrentes do uso } \\
\text { de álcool e outras drogas }\end{array}$ \\
Conceito & Perfil dos usuários de álcool e outras drogas \\
Contexto & Situação de rua \\
\hline
\end{tabular}

Quadro 2 - Descrição da estratégia PCC

Assim, a pergunta de pesquisa foi elaborada: Qual é o perfil das pessoas em situação de rua com problemas de saúde mental decorrentes do uso de álcool e outras drogas.

Conforme o protocolo do Joanna Briggs Institute - $\mathrm{JBI}^{25}$, o processo de escolha dos estudos eletivos para a revisão passou por avaliação de dois revisores. Após a busca detalhada nas bases de dados e leitura dos estudos encontrados, os revisores indicaram os estudos de maior relevância e concordância conforme os critérios de inclusão e exclusão.

Nas situações em que os revisores não entraram em acordo, foi solicitada avaliação do estudo por um terceiro revisor, vinculado ao GEAD - Grupo de estudos de álcool e drogas. 


\subsection{Estratégias de busca}

A busca de estudos foi realizada nas bases PUBMED, LILACS/BVS e Google Acadêmico, uma vez que, o Manual do JBI indica a utilização de pelo menos dois bancos de dados online relevantes para o tópico.

As bases de dados utilizadas no presente estudo foram escolhidas com base nas recomendações dos manuais de pesquisa de escopo*. Desta forma, destaca-se que a PUBMED compreende um vasto acervo com grande impacto internacional, enquanto a LILACS/BVS é elementar tratando-se de literatura nacional e latinoamericana. Optou-se pelo Google Acadêmico como plataforma adjuvante na busca de material nacional.

A fim de refinar as buscas e encontrar referencias que contemplassem todos os termos pesquisados, foram empregados os booleano AND e OR, quando necessário.

No PUBMED foram eleitos estudos correspondentes aos termos do Medical Subject Terms (MeSH), em inglês: "Drug Users" OR "Drug Abusers", AND "Illicit Drugs" OR "Street Drugs" AND "Homelessness" OR "Homeless Persons" OR "Homeless People".

No portal LILACS/BVS, foi realizada primariamente a busca por título, resumo e assunto. Foram utilizados os seguintes descritores: em português "Usuários de Drogas" AND "Drogas Ilícitas" AND "Pessoas em Situação de Rua"; em espanhol "Consumidores de Drogas" AND "Drogas llícitas" AND "Personas Sín Hogar"; e em inglês, "Drug Users" AND "Street Drugs" OR "Illicit Drugs" AND "Homeless Persons".

Abaixo, segue a Quadro 3 contendo o resumo das bases de dados selecionadas e respectivas palavras-chave e descritores estabelecidos, conforme 0 PCC. 


\begin{tabular}{|l|l|l|l|}
\hline & População & Conceito & Contexto \\
\hline & $\begin{array}{l}\text { Pessoas com } \\
\text { problemas de } \\
\text { saúde mental } \\
\text { decorrentes do } \\
\text { uso de álcool e } \\
\text { outras drogas }\end{array}$ & $\begin{array}{l}\text { Perfil dos usuários de } \\
\text { álcool e outras drogas }\end{array}$ & Situação de rua \\
\hline $\begin{array}{l}\text { PUBMED } \\
\text { (MeSH Terms) }\end{array}$ & $\begin{array}{l}\text { Drug Users OR } \\
\text { Drug Abusers }\end{array}$ & $\begin{array}{l}\text { Illicit Drugs OR Street } \\
\text { Drugs }\end{array}$ & $\begin{array}{l}\text { Homelessness OR } \\
\text { Homeless Persons OR } \\
\text { Homeless People }\end{array}$ \\
\hline $\begin{array}{l}\text { LILACS/BVS } \\
\text { (DECs Terms) }\end{array}$ & $\begin{array}{l}\text { Usuários de } \\
\text { Drogas OR Drug } \\
\text { Users OR } \\
\text { Consumidores } \\
\text { de Drogas } \\
\text { Categorias: } \\
\text { M01.169 }\end{array}$ & $\begin{array}{l}\text { Drugs OR Drogas Illicitas } \\
\text { OR Drogas de Rua OR } \\
\text { Street Drugs } \\
\text { Categorias: }\end{array}$ & $\begin{array}{l}\text { Rua OR Homeless } \\
\text { Persons OR Personas Sín } \\
\text { VS2.002.001.016 }\end{array}$ \\
Hogar \\
Categorias: \\
M01.325
\end{tabular}

Quadro 3 - Resumo das bases de dados selecionadas e respectivas palavraschave e descritores estabelecidos, conforme o PCC.

A partir da determinação das palavras-chave e descritores, iniciou-se a estratégia de busca nas respectivas bases de dados eleitas. A estratégia de busca detalhada encontra-se disposta no quadro 4.

\begin{tabular}{|l|l|l|}
\hline Base & Combinação & Resultado \\
\hline Pesquisa 1 & $(((((()(($ "drug users"[MeSH Terms] OR ("drug"[All Fields] AND & 297 \\
PUBMED & "users"[All Fields]) OR "drug users"[All Fields]) AND & \\
PCC & ("homeless persons"[MeSH Terms] OR ("homeless"[All Fields] & \\
(Mesh Terms) & AND "persons"[All Fields]) OR "homeless persons"[All Fields] & \\
& OR "homeless"[All Fields] OR "homelessness"[All Fields])) OR & \\
& ("illicit drugs"[MeSH Terms] OR ("illicit"[All Fields] AND & \\
& "drugs"[All Fields]) OR "illicit drugs"[All Fields])) AND & \\
\hline
\end{tabular}




\begin{tabular}{|c|c|c|}
\hline Base & Combinação & Resultado \\
\hline & $\begin{array}{l}\text { ("homeless persons"[MeSH Terms] OR ("homeless"[All Fields] } \\
\text { AND "persons"[All Fields]) OR "homeless persons"[All } \\
\text { Fields])) OR ("illicit drugs"[MeSH Terms] OR ("illicit"[All Fields] } \\
\text { AND "drugs"[All Fields]) OR "illicit drugs"[All Fields])) AND } \\
\text { (("homeless persons"[MeSH Terms] OR ("homeless"[All } \\
\text { Fields] AND "persons"[All Fields]) OR "homeless persons"[All } \\
\text { Fields] OR "homeless"[All Fields] OR "homelessness"[All } \\
\text { Fields]) AND ("people s"[All Fields] OR "peopled"[All Fields] } \\
\text { OR "peopling"[All Fields] OR "persons"[MeSH Terms] OR } \\
\text { "persons"[All Fields] OR "people"[All Fields] OR "peoples"[All } \\
\text { Fields]))) OR ("illicit drugs"[MeSH Terms] OR ("illicit"[All } \\
\text { Fields] AND "drugs"[All Fields]) OR "illicit drugs"[All Fields] OR } \\
\text { ("street"[All Fields] AND "drugs"[All Fields]) OR "street } \\
\text { drugs"[All Fields])) AND ("homeless persons"[MeSH Terms] } \\
\text { OR ("homeless"[All Fields] AND "persons"[All Fields]) OR } \\
\text { "homeless persons"[All Fields])) OR ("illicit drugs"[MeSH } \\
\text { Terms] OR ("illicit"[All Fields] AND "drugs"[All Fields]) OR } \\
\text { "illicit drugs"[All Fields] OR ("street"[All Fields] AND "drugs"[All } \\
\text { Fields]) OR "street drugs"[All Fields])) AND (("homeless } \\
\text { persons"[MeSH Terms] OR ("homeless"[All Fields] AND } \\
\text { "persons"[All Fields]) OR "homeless persons"[All Fields] OR } \\
\text { "homeless"[All Fields] OR "homelessness"[All Fields]) AND } \\
\text { ("people s"[All Fields] OR "peopled"[All Fields] OR } \\
\text { "peopling"[All Fields] OR "persons"[MeSH Terms] OR } \\
\text { "persons"[All Fields] OR "people"[All Fields] OR "peoples"[All } \\
\text { Fields])) }\end{array}$ & \\
\hline $\begin{array}{l}\text { Pesquisa } 2 \\
\text { PUBMED } \\
\text { PCC } \\
\text { (Mesh Terms) }\end{array}$ & $\begin{array}{l}\text { ("drug users"[MeSH Terms] OR ("drug"[All Fields] AND } \\
\text { "users"[All Fields]) OR "drug users"[All Fields] OR ("drug } \\
\text { users"[MeSH Terms] OR ("drug"[All Fields] AND "users"[All } \\
\text { Fields]) OR "drug users"[All Fields] OR ("drug"[All Fields] AND } \\
\text { "abusers"[All Fields]) OR "drug abusers"[All Fields])) AND } \\
\text { ("homeless persons"[MeSH Terms] OR ("homeless"[All Fields] } \\
\text { AND "persons"[All Fields]) OR "homeless persons"[All Fields] } \\
\text { OR "homeless"[All Fields] OR "homelessness"[All Fields]) }\end{array}$ & 230 \\
\hline $\begin{array}{l}\text { Pesquisa } 3 \\
\text { PUBMED } \\
\text { PCC } \\
\text { (Mesh Terms) }\end{array}$ & $\begin{array}{l}\text { (("drug users"[MeSH Terms] OR ("drug"[All Fields] AND } \\
\text { "users"[All Fields]) OR "drug users"[All Fields]) AND } \\
\text { ("homeless persons"[MeSH Terms] OR ("homeless"[All Fields] } \\
\text { AND "persons"[All Fields]) OR "homeless persons"[All Fields] }\end{array}$ & 108 \\
\hline
\end{tabular}




\begin{tabular}{|l|l|l|}
\hline Base & Combinação & Resultado \\
\hline & $\begin{array}{l}\text { OR "homeless"[All Fields] OR "homelessness"[All Fields])) OR } \\
\text { ("homeless persons"[MeSH Terms] OR ("homeless"[All Fields] } \\
\text { AND "persons"[All Fields]) OR "homeless persons"[All } \\
\text { Fields])) AND ("illicit drugs"[MeSH Terms] OR ("illicit"[All } \\
\text { Fields] AND "drugs"[All Fields]) OR "illicit drugs"[All Fields]) } \\
\text { AND ("illicit drugs"[MeSH Terms] OR ("illicit"[All Fields] AND } \\
\text { "drugs"[All Fields]) OR "illicit drugs"[All Fields] OR ("street"[All }\end{array}$ & \\
\hline $\begin{array}{l}\text { Feelds] AND "drugs"[All Fields]) OR "street drugs"[All Fields]) } \\
\text { LILACS / BVS } \\
\text { (DECs Terms) } \\
+ \text { Categorias }\end{array}$ & $\begin{array}{l}\text { (tw:(usuários de drogas)) AND (tw:(drogas ilícitas)) AND } \\
\text { (tw:(pessoas em situação de rua)) }\end{array}$ & 17 \\
\hline $\begin{array}{l}\text { Pesquisa 5 } \\
\text { LILACS / BVS } \\
\text { (DECs Terms) }\end{array}$ & $\begin{array}{l}\text { (tw:(consumidores de drogas)) AND (tw:(drogas ilicitas)) AND } \\
\text { Espanhol }\end{array}$ & 9 \\
\hline $\begin{array}{l}\text { Pesquisa 6 } \\
\text { LILACS / BVS } \\
\text { (DECs Terms) } \\
\text { Inglêa }\end{array}$ & $\begin{array}{l}\text { Caracterização AND Usuários de drogas AND drogas ilícitas } \\
\text { AND pessoas em situação de rua }\end{array}$ & 1280 \\
\hline $\begin{array}{l}\text { Pesquisa 7 } \\
\text { Google Acadêmico } \\
\text { (2014-2019) }\end{array}$ & persons)) & 25 \\
\hline
\end{tabular}

Quadro 4 - Estratégia de busca detalhada

Ressalta-se que, apesar da presente revisão considerar artigos publicados de 2009 a 2020, no Google Acadêmico optou-se como filtro de pesquisa referencias publicadas nos últimos cinco anos (2015 - 2020), dada a amplitude de tal ferramenta e visando também a viabilização do estudo.

\subsection{Critérios de inclusão e exclusão}

Os estudos foram captados nas bases de dados entre outubro de 2019 a agosto de 2020. Consideraram-se para inclusão os seguintes critérios: 
Após a pesquisa dos artigos nas bases de dados foi realizada uma primeira seleção dos estudos com a leitura dos títulos e resumos considerando para inclusão os seguintes critérios:

I. Período: A pesquisa foi limitada a estudos publicados a partir de 2009, ano qual foi instituída a Política Nacional para a População em Situação de Rua, pelo Governo Federal;

II. Idioma: português, inglês e espanhol;

III. Disponibilidade: Textos completos na íntegra;

IV. Temática: Uso de álcool e outras drogas na população em situação de rua;

Foram determinados como critérios de exclusão:

I. Duplicação de estudos em uma ou mais bases;

II. Estudos não disponíveis Online;

III. Estudos não disponíveis na integra;

IV. Estudos sobre a população em situação de rua com foco em doença mental não relacionada ao uso de álcool e outras drogas e/ou doenças crônicas

V. Estudos com foco em infecções sexualmente transmissíveis (ISTs) em pessoas em situação de rua que apresentem ou não doença mental relacionada ao uso de álcool e outras drogas;

VI. Estudos que discorram sobre população em situação de rua e encarceramento;

VII. Estudos limitados a gênero;

VIII. Estudos limitados a faixa etária;

IX. Estudos em que o público alvo foram familiares dos usuários de pessoas com doenças mentais decorrentes do uso de álcool e drogas em situação de rua; 
X. Estudos em que a pessoa com doenças mentais decorrentes do uso de álcool e outras drogas em situação de rua encontre-se internado (hospital, comunidades terapêuticas, casas de repouso e outros.)

Baseado nos critérios impostos no protocolo de extração de dados e após de leitura de título e resumos dos itens encontrados nas bases eletrônicas eleitas pelos revisores, houve triagem e seleção de estudos por proximidade com o tema e questão central proposta por este trabalho. 


\section{RESULTADOS}

\subsection{Artigos selecionados/ elegíveis}

O total de artigos publicados, bem como os artigos elegíveis após filtragem por leitura de título e resumo, exclusão de duplicatas e respeitando os critérios de inclusão propostos pelo presente estudo estão dispostos abaixo, no quadro 5 .

\begin{tabular}{|c|c|}
\hline PUBMED & \\
\hline Pesquisa 1 & 19 \\
\hline Pesquisa 2 & 2 \\
\hline Pesquisa 3 & 0 \\
\hline LILACS / BVS & 2 \\
\hline Pesquisa 4 & 1 \\
\hline Pesquisa 5 & 2 \\
\hline Pesquisa 6 & \\
\hline Google Acadêmico & 7 \\
\hline Pesquisa 7 & 33 \\
\hline Total & 3 \\
\hline Duplicados & $\mathbf{3 0}$ \\
\hline Referências selecionadas & \\
\hline
\end{tabular}

Quadro 5 - Artigos incluídos após a leitura dos títulos e resumos

A princípio, 30 referências foram selecionadas após leitura de título e resumo. Destas, 3 foram excluídas por duplicata em uma ou mais bases e outras 3 referencias foram excluídas pela não disponibilização de texto completo.

Salientamos ainda que optamos por trabalhos publicados em formato de artigo. Este critério foi adotado visando a otimização da extração de dados e categorização de conceitos, uma vez que os resultados de pesquisa na plataforma Google Acadêmico apontaram para diversos estudos compatíveis com os critérios 
estabelecidos para seleção de leitura completa, porém em formatos de dissertação, monografia, trabalho de conclusão de curso ou capítulo de livro.

Figura 2 - Processo de seleção de estudos
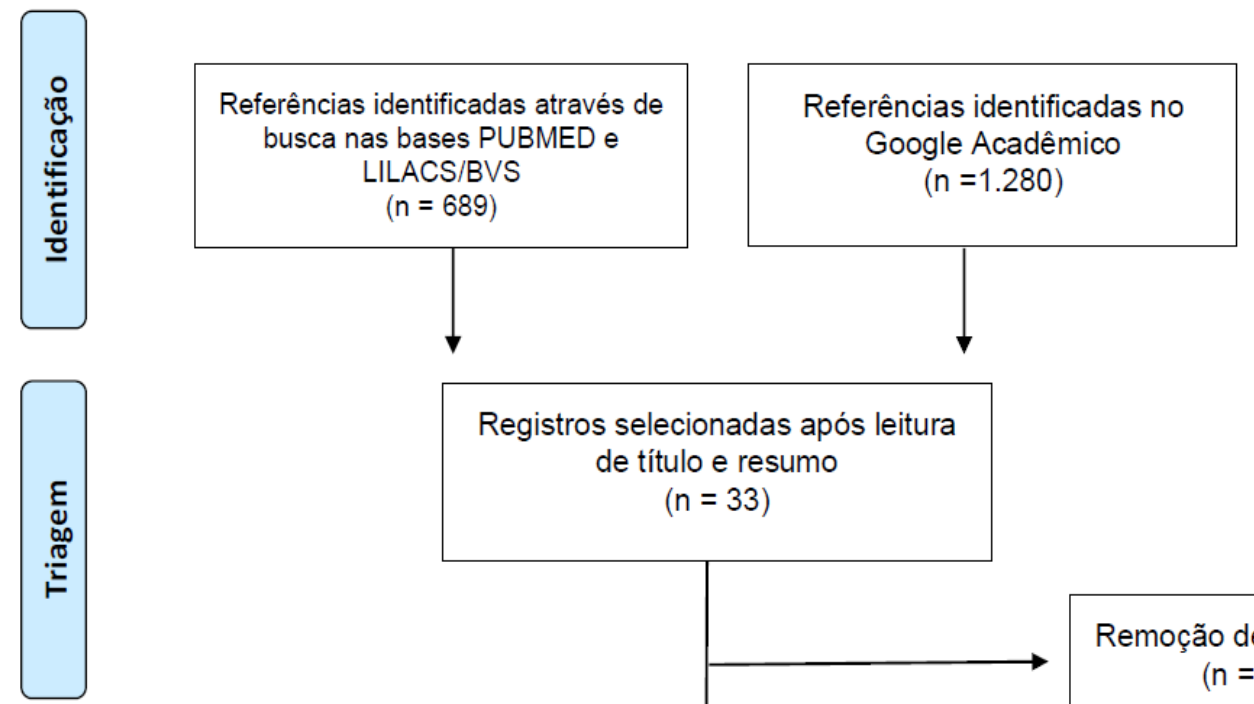

Registros selecionadas após leitura de título e resumo

$(n=33)$
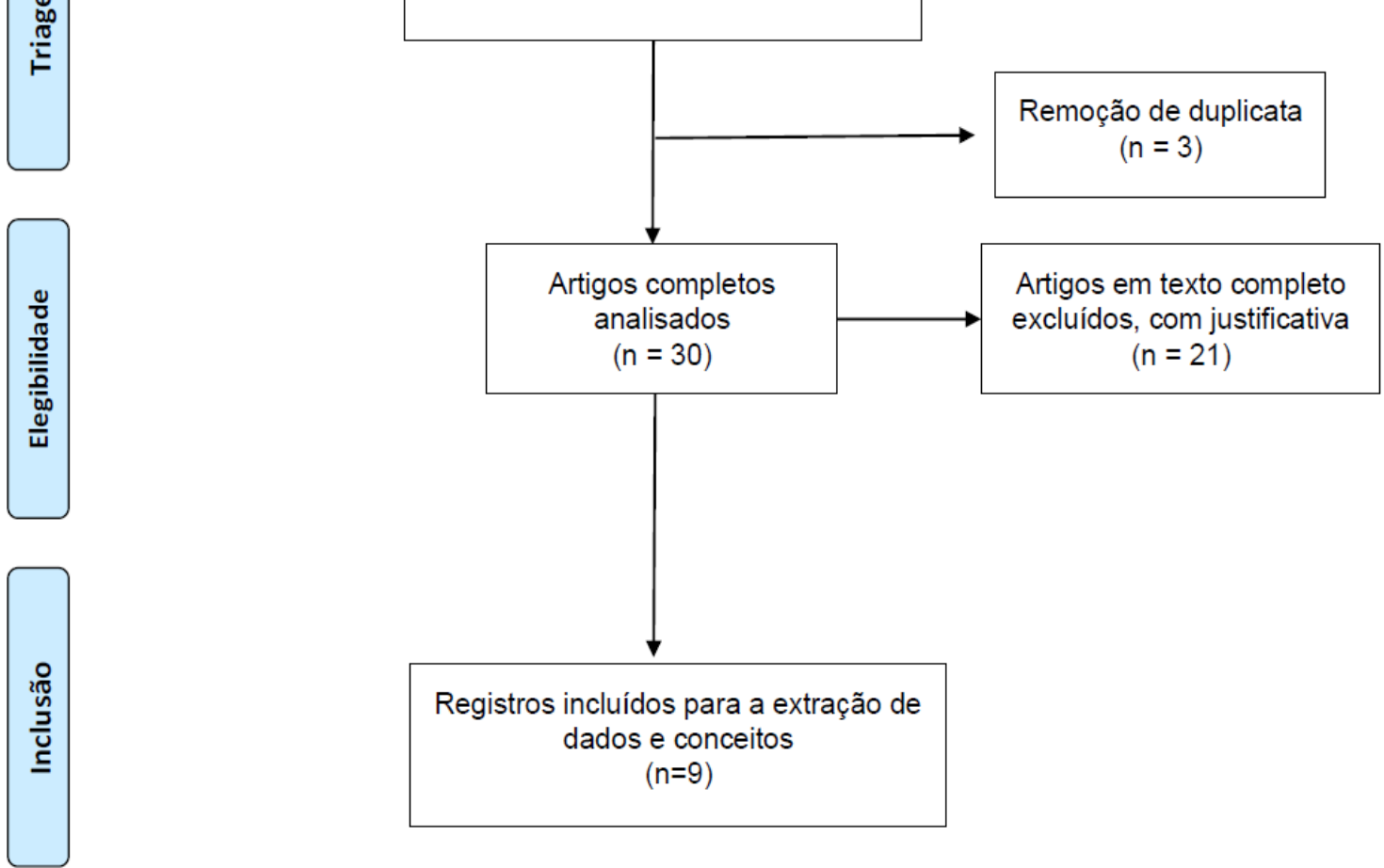

De acordo com o diagrama do processo de seleção de estudos (vide ilustração 2), dos 30 registros selecionados para análise, 21 artigos foram excluídos por não contemplarem a pergunta da revisão e o PCC.

Segue abaixo quadro com os nomes dos artigos excluídos: 


\begin{tabular}{|c|c|}
\hline 1 & $\begin{array}{l}\text { Prevalence of Mental Disorders and Addictions among Homeless People in the Greater Paris } \\
\text { Area, France }\end{array}$ \\
\hline 2 & Gênero, violência e viver na rua: vivências de mulheres que fazem uso problemático de drogas \\
\hline 3 & $\begin{array}{l}\text { The Quest to Extend Health Services to Vulnerable Substance Users in Rio de Janeiro, Brazil in } \\
\text { the Context of an Unfolding Economic Crisis }\end{array}$ \\
\hline 4 & Compreensão da vivência de mulheres em situação de rua \\
\hline 5 & Characteristics of Homeless Youth who Use Cocaine and Methamphetamine \\
\hline 6 & The Social Context of Homeless Men's Substance Use \\
\hline 7 & Personal Network Correlates of Alcohol, Cigarette, and Marijuana Use Among Homeless Youth \\
\hline 8 & Social and Structural Barriers to Housing Among Street-Involved Youth Who Use Illicit Drugs \\
\hline 9 & The Social Context of Homeless Women's Alcohol and Drug Use \\
\hline 10 & $\begin{array}{l}\text { Homelessness Independently Predicts Injection Drug Use Initiation among Street-involved Youth } \\
\text { in a Canadian setting }\end{array}$ \\
\hline 11 & Shared Risk: Who Engages in Substance Use with American Homeless Youth? \\
\hline 12 & $\begin{array}{l}\text { The Effect of Victimization, Mental Health, and Protective Factors on Crime and Illicit Drug Use } \\
\text { among Homeless Young Adults }\end{array}$ \\
\hline 13 & Perfil de drogadição e práticas sociais entre moradores de rua \\
\hline 14 & $\begin{array}{l}\text { Moving into an urban drug scene among people who use drugs in Vancouver, Canada: Latent } \\
\text { class growth analysis. }\end{array}$ \\
\hline 15 & $\begin{array}{l}\text { Risk behaviour determinants among people who inject drugs in Stockholm, Sweden over a 10- } \\
\text { year period, from } 2002 \text { to } 2012\end{array}$ \\
\hline 16 & Substance use among persons with homeless experience in primary care \\
\hline 17 & $\begin{array}{l}\text { Territorialidade dos usuários de crack em situação de rua e suas redes de apoio social no } \\
\text { município do Rio de Janeiro }\end{array}$ \\
\hline 18 & $\begin{array}{l}\text { Housing instability among people who inject drugs: results from the Australian needle and } \\
\text { syringe program survey }\end{array}$ \\
\hline 19 & $\begin{array}{l}\text { The association between social marginalisation and the injecting of alcohol amongst IDUs in } \\
\text { Budapest, Hungary }\end{array}$ \\
\hline 20 & Homeless in Dhaka: Violence, Sexual Harassment, and Drug-abuse \\
\hline 21 & $\begin{array}{l}\text { Differences in sociodemographic, drug use and health characteristics between never, former and } \\
\text { current injecting, problematic hard-drug users in the Netherlands. }\end{array}$ \\
\hline
\end{tabular}

Quadro 6 - Artigos excluídos após leitura completa 
Em relação aos 21 artigos descartados após leitura completa, destaca-se que:

- Quatro artigos analisados (2, 4, 6 e 9) eram limitados a gênero, sendo que três deles faziam recortes sobre a caracterização de mulheres em uso abusivo de álcool e drogas em situação de rua.

- Em seis artigos a limitação de idade para composição da amostra estudada foi adotada $(5,7,8,10,11$ e 12). A população alvo em todos os artigos variou entre idades de 13 a 26 anos, período transitivo entre adolescência e vida adulta. Ressalta-se ainda que os artigos 8 e 10 são derivados do estudo de coorte canadense At-risk Youth Study (ARYS);

- Um artigo (1) abordou a temática do uso de álcool e outras drogas na população em situação de rua de forma secundária ao acometimento de doenças mentais no mesmo público;

- Dois artigos (3 e 16) eram voltados para o acesso a serviços de saúde pelos usuários de álcool e outras drogas em situação de rua ou vulnerabilidade de moradia;

- A população alvo de um dos artigos encontrava-se internada em uma instituição de reabilitação (13);

- O processo de trabalho do Consultório na Rua pela visão dos usuários de álcool e outras drogas em situação de rua e trabalhadores de saúde foi o eixo central de um dos artigos descartados (17);

- Dois artigos dissertam sobre a mobilidade residencial de pessoas em uso problemático de substâncias, porém ambos não tratam exclusivamente da situação de rua $(14,18)$;

- Quatro artigos decorrem de comportamentos de risco relacionados ao uso de álcool e outras drogas, mas apesar de abordar as vunerabilidades enfrentadas por esta população, não tem como principal contexto a situação de rua $(15,19,20$ e 21$)$.

Conforme já exposto pelo diagrama do processo de seleção de estudos (figura 2), baseado e adaptado da declaração PRISMA ${ }^{25}$, após análise, 9 artigos corresponderam aos critérios de elegibilidade propostos. 
Dados bibliométricos referentes aos artigos que foram incluídos no presente estudo, após leitura completa de texto e análise do mesmo pelos revisores, encontram-se no quadro 7.

\begin{tabular}{|c|c|c|c|c|c|}
\hline Artigo & Título & Autores & Base & País & Ano \\
\hline$\overline{A 1}$ & $\begin{array}{l}\text { Sociodemographic Characteristics, Patterns } \\
\text { of Crack Use, Concomitant Substance Use } \\
\text { Disorders, and Psychiatric Symptomatology } \\
\text { in Treatment-Seeking Crack-Dependent } \\
\text { Individuals in Brazil }\end{array}$ & $\begin{array}{l}\text { Miguel AQC } \\
\text { et al. }^{29}\end{array}$ & PUBMED & BRASIL & 2018 \\
\hline A2 & $\begin{array}{l}\text { Substance Use and Psychological Distress } \\
\text { Is Related With Accommodation Status } \\
\text { Among Homeless Immigrants }\end{array}$ & $\begin{array}{l}\text { Navarro- } \\
\text { Lashayas } \\
\text { MA, Eiroa- } \\
\text { Orosa FJ }{ }^{30}\end{array}$ & PUBMED & Espanha & 2017 \\
\hline A3 & $\begin{array}{l}\text { Vulnerabilidades clínicas e sociais em } \\
\text { usuários de crack de acordo com a situação } \\
\text { de moradia: um estudo multicêntrico em } \\
\text { seis capitais brasileiras }\end{array}$ & $\begin{array}{l}\text { Halpern SC } \\
\text { et al. }{ }^{31}\end{array}$ & PUBMED & Brasil & 2017 \\
\hline A4 & $\begin{array}{l}\text { Social conditions of becoming } \\
\text { homelessness: qualitative analysis of life } \\
\text { stories of homeless peoples }\end{array}$ & $\begin{array}{l}\text { Mabhala } \\
\text { MA et a. }\end{array}$ & PUBMED & Inglaterra & 2017 \\
\hline A5 & $\begin{array}{l}\text { Usuários de crack em situação de rua - } \\
\text { características de gênero }\end{array}$ & $\begin{array}{l}\text { Vernaglia } \\
\text { TVC et al }\end{array}$ & PUBMED & Brasil & 2015 \\
\hline A6 & $\begin{array}{l}\text { Pessoas em situação de rua: caracterização } \\
\text { e contextualização por pesquisa censitária }\end{array}$ & $\begin{array}{l}\text { Húngaro AA } \\
\text { et al. }^{34}\end{array}$ & LILACS/BVS & Brasil & 2020 \\
\hline A7 & $\begin{array}{l}\text { Territórios psicotrópicos na região central da } \\
\text { cidade de Porto Alegre, RS, Brasil }\end{array}$ & $\begin{array}{l}\text { Raupp L, } \\
\text { Adorno } \\
\text { RCF }^{35}\end{array}$ & LILACS/BVS & Brasil & 2015 \\
\hline A8 & $\begin{array}{l}\text { Desigualdade social em saúde na } \\
\text { população em situação de rua na cidade de } \\
\text { São Paulo }\end{array}$ & $\begin{array}{l}\text { Barata RB, } \\
\text { Carneiro et } \\
\text { al. }^{36}\end{array}$ & $\begin{array}{l}\text { Google } \\
\text { Acadêmico }\end{array}$ & Brasil & 2015 \\
\hline A9 & $\begin{array}{l}\text { Redução de riscos e danos: ações em } \\
\text { saúde com pessoas em situação de rua no } \\
\text { interior nordestino }\end{array}$ & $\begin{array}{l}\text { Matoso LML } \\
\text { et al. }\end{array}$ & $\begin{array}{l}\text { Google } \\
\text { Acadêmico }\end{array}$ & Brasil & 2018 \\
\hline
\end{tabular}

Quadro 7 - Artigos eleitos submetidos a análise 
Os artigos selecionados foram submetidos a extração de dados, por meio de um instrumento (Apêndice A) criado com o objetivo de otimizar o processo de categorização de informações.

O instrumento compreende dados referentes a identificação dos estudos (título, autores, ano de publicação, país de origem, base de dados e descritores), metodologia de estudo, método aplicado para obtenção dos resultados, objetivo e População, Conceito e Contexto (PCC).

A aplicação do instrumento possibilitou também a identificação de elementos cruciais para a construção do perfil de pessoas em situação de rua com doença mental decorrente do uso álcool e outras drogas.

A fim de responder o objetivo principal deste trabalho foram extraídos dos estudos analisados dados sobre raça, idade, gênero, estado civil, nível de escolaridade e situação ocupacional.

Em relação a situação de rua, o instrumento permitiu determinar o tempo médio e causas da permanência na rua, além de identificar se dispositivos de auxílio social são utilizados pela população alvo, seja para proteção (pernoitar e higiene) ou alimentação e sua frequência.

O consumo de álcool e outras drogas também são elementos categorizados na extração de dados. Com o instrumento, buscou identificar quais as drogas mais utilizadas, padrão de uso e programas e/ou dispositivos de saúde utilizados (se utilizados).

Os resultados referentes a extração de dados estão dispostos no apêndice A. 


\section{DISCUSSÃO}

Conhecer as particularidades da população em situação de rua quanto as vulnerabilidades sociais que as cercam nos permitem identificar as necessidades básicas e características essenciais para a criação de estratégias e políticas públicas efetivas, além de detectar as lacunas de conhecimento acerca do assunto.

Desta forma, colocamos em discussão os principais tópicos identificados com base na análise dos artigos escolhidos, a fim de responder os objetivos propostos por esta dissertação. Dados bibliométricos serão trazidos a debate primeiramente e, em seguida, características constituintes da população alvo do estudo. Por final, discutiremos as lacunas identificadas sobre o tema.

Em relação aos dados bibliométricos, dos nove artigos selecionados para análise, sete são brasileiros. Esse dado demonstra que a temática em questão tem sido discutida progressivamente em pesquisas por todo o país.

Ressalta-se ainda que os estudos não se limitam ao eixo Rio-São Paulo, que comumente recebe maior atenção por parte da mídia. Sendo assim, podemos destacar a rica produção bibliográfica das regiões Nordeste e Sul do país, que notoriamente contribuem para um melhor mapeamento e caracterização da população em situação de rua em uso abusivo de álcool e outras drogas. Todavia, salientamos a carência de produções bibliográficas da região Norte do país, que contemplem o tema.

Já os outros dois artigos selecionados trazem dados de países Europeus, respectivamente, Espanha e Inglaterra. $\mathrm{O}$ artigo dos autores Navarro-Lashayas e Eiroa-Orosa ${ }^{30}$ detalha a relação entre 0 uso de substancias e status de acomodação entre imigrantes em situação de rua na Espanha. O estudo destaca que a população alvo é composta majoritariamente por imigrantes oriundos da África (regiões do Magrebe e África Subsaariana), trazendo a debate características ímpares e vulnerabilidades desta população em específico.

Já o artigo de Mabhala, Yohannes e Griffith ${ }^{32}$ por sua vez, traz narrativas da população nativa do Reino Unido. Assim, foi possível analisar as particularidades e 
adversidades enfrentadas pelas pessoas em situação de rua provenientes do país, destacando o uso problemático de substâncias e violência. Ressalta-se que os relatos dos participantes bem como demais dados apresentados pelo artigo carregam importantes contribuições sobre a realidade europeia, possibilitando a comparação sobre as características sociodemográficas evidenciadas pelo estudo em relação ao observado em outros países.

No entanto reforçamos que a maior parte das publicações - incluindo os estudos que foram descartados após leitura completa - são oriundos das Américas do Norte e Sul e Europa, evidenciando a escassez/falta de acesso a estudos em populações de outros continentes, principalmente Ásia e Oceania e também trabalhos mais detalhados sobre a população do continente africano.

Ainda, é possível observar o avanço de publicações sobre a população em situação de rua e uso de álcool e outras drogas. Enfatiza-se que, embora o presente estudo tenha optado pela busca de artigos publicados a partir de 2009 (ano marco da PNPSR), nota-se crescimento progressivo do número de publicações sobre o tema em questão nas bases de dados a partir de 2015.

Este dado é claramente evidenciado quando analisamos a amostra de artigos eleitos para revisão, onde das nove referencias escolhidas três foram publicadas no ano de 2015; duas no ano de 2017; três em 2018; e a mais recente, em 2020.

Os artigos escolhidos foram publicados em revistas nas áreas de redução de danos, drogas psicoativas, saúde pública, psicologia e enfermagem. Isso reforça a importância de que pessoas em vulnerabilidade social necessitam de uma abordagem multidisciplinar, para que suas particularidades sejam compreendidas como um todo.

A análise dos artigos eleitos também possibilitou debater características significativas para a construção do perfil de usuários de alcool e outras drogas em situação de rua.

O indicador cor/raça esteve presente em apenas cinco dos nove artigos analisados. Contudo, os trabalhos que continham tal informação apontaram como 
predominante a cor parda/preta. Ressalta-se que todos os artigos que apresentaram o indicador em questão são publicações brasileiras e que devido à falta deste indicador nos estudos internacionais analisados não foi possível realizar um comparativo entre características predominantes na população alvo no Brasil e demais países.

Entretanto este dado reforça a importância da criação de políticas públicas inclusivas para a população negra brasileira, visto que ainda sofre com o estigma da exclusão, segregação social ${ }^{38}$ e maiores dificuldades para acessar serviços de saúde e de cunho social.

Em relação ao indicador idade, foi observado que a faixa etária predominante nos estudos varia entre 30-59 anos, evidenciando que grande parte da população em situação de rua usuária de álcool e outras drogas é composta por adultos. Ressalta-se que nos estudos europeus a média de idade girou em torno de 32 anos no estudo espanhol e 38.8 anos no estudo inglês, indicando que os dados analisados em artigos brasileiros coincidem com dados indicados nos perfis traçados por estudos internacionais.

É necessário destacar que todos os artigos analisados abordaram pessoas maiores de 18 anos, não contemplando assim dados referentes a crianças e adolescentes usuárias de álcool e outras drogas em situação de rua.

Entende-se que tal variável poderia alterar a caracterização proposta pelo presente estudo em relação a idade/faixa etária, porém optamos pela decisão em não incluir estudos sobre grupos específicos, em caráter de não limitar e/ou comprometer a escolha de artigos.

Ao tratar-se de gênero, o sexo masculino aparece em evidência nos artigos analisados. Dos estudos que continham este indicador, apenas o artigo de Vernaglia, Vieira e $\mathrm{Cruz}^{33}$ apresentou um número de mulheres sobressalente ao de homens.

No artigo A7, os autores Raupp e Adorno ${ }^{35}$ descrevem que mesmo em menor quantidade, foi perceptível a presença de mulheres usuárias de álcool e outras 
drogas em situação de rua no território observado. Ainda destacam que o número reduzido de mulheres em relação aos homens pode ser justificado devido ao fato de que muitas usuárias transitam nas regiões adjacentes ao território, em pontos de prostituição.

Ainda sobre gênero, podemos observar algumas mudanças importantes na caracterização de pessoas em situação de rua. Barata, Carneiro e Ribeiro ${ }^{36}$ descrevem que foi observado a prevalência do gênero masculino entre pessoas em situação de rua que pernoitavam em vias públicas; porém, em relação as pessoas em situação de rua que utilizavam dispositivos sociais como albergue municipal para pernoitar, o gênero predominante é o feminino.

A alteração de gênero predominante quando mudado o contexto em que os indivíduos se encontram pode ser justificada pelo medo de violência (física, sexual, verbal), uma vez que muitas das mulheres que se encontram em situação de rua estão expostas. Desta maneira, o pernoitar no albergue promove uma maior sensação de segurança a estas mulheres, além é claro de propiciar maior conforto em comparação com pernoitar na rua.

Outro dado relevante a ser discutido é o crescente número de publicações onde o público alvo são mulheres em uso abusivo de álcool e outras drogas onde o contexto é a situação de rua. Apesar do estudo em questão ter optado por não restringir a pesquisa a artigos que limitassem gênero, é importante salientar o progressivo aumento de estudos sobre mulheres e tais situações de vulnerabilidade e a qualidade das produções bibliográficas.

$A$ análise $A 5^{33}$ também trouxe outro dado importante sobre gênero, que é o paralelo entre maternidade e posição de superioridade que a mulher assume dentro das relações entre grupos de usuários de álcool e outras drogas em situação de rua. O "ser mãe" confere a estas mulheres respeito dentro do contexto em que elas se encontram. Devido a essa dinâmica, alguns relatos - do A5 - descrevem que mulheres que ainda não são mães por vezes demonstram ciúmes da posição em que as outras assumem perante o grupo. 
Relações entre poder e gênero ainda permeiam a dinâmica de casais. Os usuários por vezes veem como função do homem prover as necessidades da mulher, como conseguir dinheiro, comida, proteção e até possibilitar o uso de SPAs.

Apesar de muitas vezes usuários de álcool e drogas em situação de rua se relacionarem entre membros do mesmo grupo, ao analisarmos os artigos selecionados, constatamos que o estado civil predominantemente da população estudada é composta por pessoas solteiras. Em seguida, aparecem como indicador pessoas divorciadas/separadas.

A escolaridade é o indicador que apresenta maior divergência entre pesquisas realizadas na população brasileira comparada com os artigos internacionais, em especial a análise $A 4^{33}$.

Majoritariamente, as publicações brasileiras analisadas apontam que a população alvo possui ensino fundamental incompleto. Já as referências internacionais indicam um panorama diferente.

$\mathrm{Na}$ análise $\mathrm{A} 2^{32}$ (estudo espanhol realizado com imigrantes) o nível de instrução entre os participantes do estudo é de ensino fundamental, como descrito na bibliografia brasileira, entre pessoas que pernoitam em vias públicas. Porém, quando analisamos o indicador escolaridade entre as pessoas em situação de rua que pernoitam em albergues ou hostels, o nível educacional sobe para ensino médio.

Por sua vez, a análise $\mathrm{A} 4^{32}$, realizada na Inglaterra, nos aponta que o nível educacional predominante corresponde ao ensino médio, destacando que alguns participantes possuem inclusive nível superior.

O nível mais baixo de escolaridade apresentado nos artigos oriundos do Brasil pode ser justificado por meio do indicador de educação brasileira, que apontam para um alto índice de crianças e jovens fora da escola, ingresso tardio no sistema educacional, baixo aproveitamento/desempenho escolar e defasagem idade/série. 
Ressalta-se mais uma vez que, apesar da $A 2^{32}$ ser realizada na Espanha, o público analisado é proveniente de outros países. Portanto, é provável que se a amostra analisada pelos pesquisadores fosse composta da população nativa do país o panorama de dados educacionais fosse ainda mais parecido com os dados apresentados pelo estudo inglês, consequentemente, mais distantes da realidade brasileira.

Características sobre emprego/ocupação exercida evidenciam o desemprego e desalento, principalmente entre as referências nacionais. Apesar de grande parte dos usuários de álcool e outras drogas estarem inseridos no contexto de desemprego e desalento, muitos ainda exercem os chamados subempregos: empregos de baixa qualificação, com remuneração baixa, ou emprego informal sem vínculos e sem garantia ${ }^{36}$. Desta forma se faz comum dentro da população de estudo a realização de atividades de mão de obra eventual (famosos bicos) e trabalho informal (como coleta de recicláveis e guardar carros/flanelinha em vias públicas).

A mendicância também aparece como forma de sobrevivência, tal qual a prostituição. Esta última apesar de mais comum entre mulheres também tem sido vivenciada pelos homens.

Outra fonte de trabalho informal/obtenção de renda apresentada especificamente na $A 7^{35}$ é a confecção artesanal de cachimbos para o consumo de drogas, feito e comercializado entre próprios usuários.

Os dados presentes na análise dos artigos contemplaram também questões especificas sobre a situação de rua, como causa da permanência, tempo médio em situação de rua e dispositivos de auxílio social utilizados.

Sete dos nove artigos eleitos indicam o uso de drogas como fator determinante para a permanência na rua. Em seguida, desentendimentos familiares (geralmente relacionados pelo uso de drogas antes do ingresso na situação de rua), morte/perda de ente querido, desemprego e problemas financeiros. 
Conforme os dados analisados, o tempo médio de permanência na situação de rua foi de 2 a 5 anos. Já os dispositivos de auxílio social mais utilizados foram albergues municipais. Os artigos A2 e A4 citam também hostels como dispositivos utilizados pela população em situação de rua.

As análises $A 3^{31}, A 6^{34}$ e $A 8^{36}$ destacam a necessidade de programas e dispositivos de auxílio social no Brasil. Da mesma maneira a A2 salienta a necessidade de programas voltados para o auxílio social da população vulnerável na Espanha.

As análises sobre o consumo de drogas pela população em situação de rua evidenciaram a prevalência de substâncias como álcool, tabaco, crack, maconha, cocaína e inalantes.

Consideradas drogas socialmente aceitas, o álcool e o tabaco aparecem nos estudos analisados como substâncias de vasto uso entre a população em situação de rua. Os estudos que contemplam indicadores referentes ao padrão de uso apontam que o consumo de ambas das drogas é realizado diariamente, diversas vezes em associação a outra SPA.

O uso de álcool ainda apresenta uma problemática mais densa quando comparado ao uso do tabaco pela população em situação de rua, visto seu viés social.

No artigo A2 os autores citam que o abuso de álcool aparece como uma forma de suportar as mazelas da vida na rua, como fome, frio e violência. No mesmo artigo, o uso de álcool aparece como estratégia de socialização.

O A2 ${ }^{30}$ também traz a reflexão sobre o abuso de álcool e questões culturais/religiosas. Como citado anteriormente, a Espanha recebe muitos imigrantes oriundos do continente africano, onde grande parte da população é adepta ao islamismo, religião que possui rígidas proibições sobre a ingestão de bebidas alcoólicas. O discurso de um dos profissionais de saúde ouvido no grupo focal traz a debate essa problemática sobre a normalização de alguns comportamentos decorrentes da vivência nas ruas. 
Segundo a narrativa do profissional, essa normalização de alguns comportamentos - como o uso abusivo de álcool - se faz necessária para que se consiga sobreviver a vida nas ruas, de maneira que, mesmo que a pessoa em situação de rua não deva beber (por questões religiosas) ela acaba fazendo pela justificativa de que está nas ruas. O profissional também relata que muitas destas pessoas se utilizam do argumento de que ao sair das ruas irão abandonar o uso de álcool.

A produção literária brasileira tem trazido igualmente debate sobre 0 uso abusivo de álcool pela população em situação de rua. Nas publicações analisadas é possível identificar a relação da dependência do álcool com outras simultaneamente a dependência de outras substancias, como no caso do crack; e também como maneira de sobrevivência nas ruas, visto que, da mesma forma que $\circ$ A2, alguns autores apresentam evidencias de que o álcool por vezes é utilizado em grande escala pelos usuários com a finalidade de socialização e estratégia de enfrentamento das adversidades da vida nas ruas.

Em três dos nove artigos analisados, a dependência de crack aparece como droga principal de uso. Isso se deve pelo fato de que o crack - assim como o álcool aparecer como droga amplamente utilizada pela população em situação de rua, por possuir baixo custo comparado a demais drogas e alto grau de dependência.

Dados apresentados na análise A1 indicam que o padrão de uso diário do crack seja de aproximadamente 12 pedras. Por tratar-se de um dado subjetivo, entende-se que esta variável pode apresentar grande alteração quando analisada em diferentes contextos.

Nesta situação explanada pela $A 1$, os dados da amostra foram coletados na cidade de São Paulo/SP, na região da Cracolândia, que é famosa pela grande concentração de usuários. Infelizmente este dado não foi apresentado com precisão nos demais artigos, o que contribuiria significantemente para a discussão.

Ressalta-se ainda que grande parte da produção bibliográfica acerca da dependência do crack pela população em situação de rua é proveniente do Brasil. 
Outra droga utilizada em larga escala dentro da população em situação de rua é a maconha, onde seu uso é apresentado diversas vezes como adjunto ao uso de álcool e crack. Dados sobre o padrão de uso da maconha por parte das pessoas em situação de rua não foi explanado nos artigos analisados.

Cocaína e inalantes também são citados como drogas de escolha da população em situação de rua, sobretudo em estudos brasileiros, embora em menor escala quando comparado ao uso de álcool e crack.

A análise de artigos possibilitou traçar o comparativo entre drogas mais utilizadas pela população em situação de rua no Brasil e na Europa, através dos estudos A2 sobre a experiencia espanhola e A4 sobre a experiencia inglesa.

O álcool aparece como a droga mais utilizada e é amplamente discutido em todas as publicações analisadas. O tabaco também aparece em grande parte das publicações, porém seu uso é discutido em menor escala.

O crack aparece em todas as publicações brasileiras analisadas. Este dado reforça a importância da criação de estratégias de cuidado em saúde para a população em uso problemático da substância e a estruturação de políticas públicas cada vez mais acessíveis a população em situação de rua.

O uso de substâncias como a maconha e cocaína aparecem tanto em estudos brasileiros quanto no estudo inglês que fora analisado na presente revisão. Já o uso de inalantes aparece apenas em estudos brasileiros.

As características apresentadas no estudo espanhol sobre as SPAs mais utilizadas na população alvo nos traz um dado que diverge do perfil brasileiro e inglês.

Além é claro, do amplo uso de álcool pela população em situação de rua, o haxixe aparece como SPA amplamente utilizada. O padrão de uso do haxixe descrito pela A2 é de três ou mais vezes por semana. 
Em relação aos programas e dispositivos de saúde mais utilizados pelos usuários, os estudos A2 e A4 não apresentaram tais dados. Sendo assim, apenas estudos nacionais apresentam essa informação.

Frequentemente os usuários relatam a utilização do CAPS e CAPS AD, bem como UBSs/ESFs e unidades de pronto atendimento (UPA). O acesso aos serviços de saúde da população em situação de rua também se dá pelo trabalho dos Consultórios na Rua.

Este dado vem de encontro com o que é proposto pelas diretrizes pelo SUS, uma vez que o acesso a saúde deve ser estendido a todos de maneira universal, integral e respeitando a equidade.

Ainda assim, a criação e implementação de programas e dispositivos com a finalidade de atingir grupos em vulnerabilidade se faz uma medida urgente, dado que população em situação de rua em uso abusivo de álcool e outras drogas têm apresentado crescimento acelerado, tanto no Brasil quanto no mundo.

A análise dos estudos eleitos possibilitou a identificação das lacunas a respeito do tema. Desta forma, destacamos que apesar de rica a produção de estudos brasileiros sobre a população usuária de álcool e outras drogas em situação de rua, se faz necessário o aumento de publicações com o objetivo de descrever as características sociodemográficas da população em questão, para que a elaboração de políticas públicas e programas seja aperfeiçoada.

Chamamos a atenção principalmente para a escassez de publicações sobre populações em situação de rua e uso abusivo de drogas provenientes das regiões Norte e Centro-Oeste do país. Acreditamos que estas regiões podem acrescentar informações valiosas para a construção de um perfil sobre a população usuária de álcool e outras drogas em situação de rua do país, ainda mais considerando suas singularidades.

Estudos internacionais onde o foco na investigação seja as características sociodemográficas de usuários de álcool e drogas em situação de rua também se 
fazem necessários. Desta forma seria possível traçar um comparativo entre as características da população brasileira e demais países.

Em relação aos indicadores utilizados para a extração de dados, destacamos que a falta de dados referente a cor/raça merece atenção, pois como observado pelos autores do artigo $A 9^{37}$, estes dados servem para mensuração do grau de exposição de indivíduos a fatores sociais.

Outro item que poderia ser melhor trabalhado são os indicadores referentes a padrão de uso de substâncias. Poucos estudos apresentam tal dado. Mesmo sendo uma variável subjetiva, tal dado poderia enriquecer a construção do perfil sociodemográfico proposto.

Considerando assim a análise de conteúdo publicado acerca do tema central proposto por esta dissertação, entende-se que apesar das lacunas de conhecimento identificadas, foi possível alcançar o objetivo proposto, através da criação de um perfil que englobe características sociodemográficas sobre a população em situação de rua e suas particularidades. 


\section{CONSIDERAÇÕES FINAIS}

O uso de álcool e outras drogas é um notório problema de saúde pública enfrentado mundialmente. Sua complexidade é agravada quando o associamos este uso problemático de substâncias a situações de vulnerabilidade social, como é o caso da situação de rua.

Estudos de caracterização são imprescindíveis para melhoria da qualidade de vida das pessoas em situação de rua com problemas de saúde mental decorrentes do uso de álcool e outras drogas, uma vez que possibilitam recursos para a criação de estratégias efetivas na garantia de direitos e no combate adversidades sociais e de saúde enfrentadas.

Por meio da análise proposta pela presente revisão foi possível observar dados importantes sobre das características da população em situação de rua em uso de álcool e outras drogas.

Primeiramente, destaca-se que o Brasil detém um rico acervo de publicações referentes ao tema. Apesar de muitos trabalhos evidenciarem a realidade vivenciada na cidade de São Paulo/SP a partir da região da cracolândia e das comunidades do Rio de Janeiro/RJ, a produção cientifica acerca do tema tem se expandido para diversas localidades do território brasileiro.

Destacamos aqui produções das regiões Nordeste e Sul, que contribuem positivamente para a caracterização de pessoas em uso de álcool e outras drogas que se encontram em situação de rua, considerando as particularidades de seu território e permitindo a criação de um perfil condizente com um país tão extenso como o Brasil.

Ressalta-se, porém, que dados sobre a realidade vivenciada na região Norte e Centro-Oeste são escassos, indicando falha no registro de dados de pessoas oriundas destas regiões.

Em relação a publicações internacionais, fica evidenciado que grande parte dos estudos é proveniente da América do Norte e Europa. No entanto, a produção bibliográfica do primeiro não se encaixou nos critérios propostos para elegibilidade desta revisão. 
Já em relação aos estudos europeus, destaca-se a qualidade e complexidade presente nos relatos publicados. Entretanto, salientamos que era esperado o alcance de publicações que relatassem os perfis em outros continentes também, como África, Ásia e Oceania, além de outros países da américa latina fora o brasil.

Mesmo com as adversidades na localização de artigos foi possível a extração de dados para a construção de um perfil que comtemple as principais características observadas na população em situação de rua em uso de álcool e outras drogas.

Observa-se que a população ainda é composta majoritariamente por homens, embora cada vez mais mulheres também ingressem na situação de rua e abuso de drogas.

Indicadores de idade demonstram que a média entre os estudos analisados é de 30 a 59 anos. Já sobre o indicador cor/raça, evidencia-se a cor parda. É importante frisar que os dados referentes a cor/raça estavam presentes apenas em estudos brasileiros.

Marcadores referentes ao estado civil indicam que a população é composta predominantemente por solteiros. O nível de escolaridade observado é fundamental incompleto.

Em relação a ocupação, o número de desempregados ainda é sobressalente. O tempo médio de vivência em situação de rua foi apontado entre 2 a 5 anos; e as causas foram o uso de drogas e desavenças familiares.

Dispositivos mais utilizados para apoio social são albergues e hostels.

Sobre o uso de drogas, destaca-se o amplo e alto consumo de álcool entre pessoas em situação de rua. Em seguida aparecem tabaco e crack como drogas mais utilizadas.

Dados sobre o padrão médio do uso de drogas foram pouco apresentados nos artigos analisados. Porém os relatos demonstram que as três principais drogas de uso na rua - álcool, tabaco e crack - são utilizadas diariamente.

Os dispositivos e programas voltados para saúde mais utilizados são os CAPS e CAPS AD, UBS/ESF, UPA e Consultório na Rua. 
Conclui-se assim, que os dados extraídos com base na análise de artigos foram satisfatórios, por ora, para a caracterização da população em situação de rua com problemas de saúde mental decorrente do uso de álcool e outras drogas.

Espera-se que, com o aumento progressivo de publicações sobre o tema evidenciados nos últimos cinco anos, seja possível a extração de dados mais minuciosos que venham acrescer a caracterização da população em estudo. 


\section{REFERÊNCIAS}

1 Silva ATMC, Barros S, Oliveira MAF. Políticas de saúde e de saúde mental no Brasil: a exclusão/inclusão social como intenção e gesto. Rev Esc Enferm USP 2002; 36(1): 4-9. [Acesso em: 13 out. 2020]; Disponível em: https://doi.org/10.1590/S0080-62342002000100002

2 Mângia EF, Nicácio, F. Terapia Ocupacional em Saúde Mental: tendências principais e desafios contemporâneos. In: Prado De Carlo MMR, Bartalotti CC (org.). Terapia Ocupacional no Brasil: fundamentos e perspectiva. São Paulo: Plexus Editora, 2001.

3 Brasil. Lei No 10.216, DE 6 DE ABRIL DE 2001. Dispõe sobre a proteção e os direitos das pessoas portadoras de transtornos mentais e redireciona 0 modelo assistencial em saúde mental. Diário Oficial da União, Brasília, 9 abr. 2001. Seção 1:2

4 Junior HPOS, Silveria MFA. Práticas de cuidado produzidas nos serviços de residências terapêuticas: percorrendo os trilhos de retorno à sociedade. Revista Escola de Enfermagem da USP, 43 (4), p. 788-95, 2009.

5 Spadoni L, Machado Júnior CP, Silva Neto C, Carvalho J, Gonçalves C. O medo e a polidrogadição em moradores de rua usuários de crack. Atas: Inv. Qual. em Ed. [Internet] 2014 [Acesso em: 02 nov. 2017]; Disponível em: http://www.proceedings.ciaiq.org/index.php/CIAIQ/article/view/506/501

6 IBGE - Instituto Brasileiro de Geografia e Estatística. População estimada: IBGE, Diretoria de Pesquisas, Coordenação de População e Indicadores Sociais, Estimativas da população residente com data de referência 10 de julho de 2019. [Internet] 2020 [Acesso em: 15 jan. 2020]; Disponível em: https://cidades.ibge.gov.br/brasil/sp/sao-paulo/panorama 
7 Leite F. Pesquisa revela que população da Cracolândia cresceu $160 \%$ em um ano. O Estado de S. Paulo. [Internet]. 2017 jun. 08 [citado em 2017 nov. 03]. Disponível em: http://sao-paulo.estadao.com.br/noticias/geral,pesquisarevela-que-populacao-da-cracolandia-cresceu-160-em-um-ano,70001832252

8 Brasil. Ministério da Saúde. Portaria no 816, de 30 de abril de 2002. Institui, no âmbito do Sistema Único de Saúde, o Programa Nacional de Atenção Comunitária Integrada a Usuários de Álcool e Outras Drogas, a ser desenvolvido de forma articulada pelo Ministério da Saúde e pelas Secretarias de Saúde dos estados, Distrito Federal e municípios. In Diário Oficial da União.[Internet]. 2020 out. 15. Disponivel em: http://bvsms.saude.gov.br/bvs/saudelegis/g

9 Zoldan LGV, Ribeiro M. O CRATOD e o tratamento da dependência química no Brasil. In: Zoldan LGV, Ribeiro M. editor. CRATOD 15 ANOS - Uma proposta de cuidado ao dependente químico. [Internet]. $1^{\underline{a}}$ ed. São Paulo: Governo do Estado de São Paulo, 2017. 374 p. [citado em 02 mar 2019] Disponível

em: http://www.saude.sp.gov.br/resources/cratod/download/cratod_15_anos.pdf

10 São Paulo (Estado). Decreto n. 59.684/2013, de 31 de outubro de 2013. Dá nova redação e acrescenta dispositivo ao Decreto no 59.164 , de 2013, que institui o Programa Estadual de Enfrentamento ao Crack, denominado Programa Recomeço, e dá providências correlatas. Diário Oficial do Estado de São Paulo. 2013; 123 (206):1.

11 São Paulo (Estado). Decreto n. 61.664, de 02 de dezembro de 2015. Reorganiza o "Programa Estadual de Enfrentamento ao Crack - Programa Recomeço", que passa a denominar-se "Programa Estadual de Políticas sobre Drogas - Programa Recomeço: uma vida sem drogas. Diário Oficial do Estado de São Paulo. 2015;224(125):1. 
12 Damatta R. A casa \& a rua: espaço, cidadania, mulher e morte no Brasil. Rio de Janeiro: Rocco, 1997

13 Abreu D. Pessoas em situação de rua, uso de drogas e o consultório de rua. [dissertação]. Florianópolis: Centro de Ciências da Saúde, Universidade Federal de Santa Catarina; 2013.

14 Brognoli FF. Trecheiros e Pardais: estudo etnográfico de nômades urbanos. 1996. [dissertação]. Florianópolis: Centro de Filosofia e Ciencias Humanas, Universidade Federal de Santa Catarina; 1996.

15 Prates JC, Prates FC e Machado S. Populações em situação de rua: os processos de exclusão e inclusão precária vivenciados por esse segmento. Temporalis [Internet]. 2011 [citado em 08 ago. 2020];11(22) n.22; Disponível em: https://periodicos.ufes.br/index.php/temporalis/article/view/1387

16 Vieira MAC, Bezerra EMR, Rosa CMM. Organizadores. População de rua: quem é, como vive, como é vista. São Paulo: Hucitec, 1992.

17 Brasil. Ministério da Saúde. Decreto nำ7.053, de 23 de dezembro de 2009. Institui a Política Nacional para a População em Situação de Rua e seu Comitê Intersetorial de Acompanhamento e Monitoramento, e dá outras providências. Diário Oficial da União. Brasília, 24 dez. 2009

18 Fraiman DP, Mello IM, Grando LH, Teixeira MB. Manual de enfermagem psiquiátrica. Rio de Janeiro: Atheneu; 1997.

19 Guimarães AN, Borba LO, Larocca LM, Maftum MA. Tratamento em saúde mental no modelo manicomial (1960 a 2000): histórias narradas por profissionais de enfermagem. Texto Contexto Enferm [Internet]. 2013 [2017 nov. 08]; Disponível em: https://www.researchgate.net/profile/Liliana_Muller_Larocca/publication/26270 
8442_Mental_health_treatment_according_to_the_asylum_model_1960_TO_ 2000_Nursing_pr

20 Brasil. Ministério da Saúde. A política do Ministério da Saúde para Atenção Integral aos usuários de álcool e outras drogas. 2a ed. Brasília: Ministério da Saúde; 2004.

21 Machado AR, Miranda SC. Fragmentos da história da atenção à saúde para usuários de álcool e outras drogas no Brasil: da justiça a saúde pública. História, Ciências, Saúde. [Internet]. 2007 [citado em 20 set. 2019];14(3); Disponível em: https://www.scielo.br/scielo.php?script=sci_arttext\&pid=S010459702007000300007

22 Alves VM. Modelos de atenção à saúde de usuários de álcool e drogas: discursos políticos e saberes práticos. Cad Saúde Pública. [Internet]. 2009 [citado em 20 set. 2019]; 25(11); Disponível em: https://www.scielo.br/scielo.php?script=sci_arttext\&pid=S0102311X2009001100002\&lang=pt

23 Brasil. Ministério da Saúde. Decreto n⒐761, de 11 de abril de 2019. Aprova a Política Nacional sobre Drogas. Diário Oficial da União. Brasília, 22 abr. 2019. Disponivel em: http://www.planalto.gov.br/ccivil_03/_ato20192022/2019/decreto/D9761.htm

24 Brasil. Ministério da Saúde. Lei oㅜ13.840, de 05 de junho de 2019. Altera as Leis nos 11.343, de 23 de agosto de 2006, 7.560, de 19 de dezembro de 1986, 9.250, de 26 de dezembro de 1995, 9.532, de 10 de dezembro de 1997, 8.981, de 20 de janeiro de 1995, 8.315, de 23 de dezembro de 1991, 8.706, de 14 de setembro de 1993, 8.069, de 13 de julho de 1990, 9.394, de 20 de dezembro de 1996, e 9.503, de 23 de setembro de 1997, os Decretos-Lei nos 4.048, de 22 de janeiro de 1942, 8.621, de 10 de janeiro de 1946, e 5.452, de 1ํ de maio de 1943, para dispor sobre o Sistema Nacional de Políticas 
Públicas sobre Drogas e as condições de atenção aos usuários ou dependentes de drogas e para tratar do financiamento das políticas sobre drogas.. Diário Oficial da União. Brasília, 06 jun. 2019. Disponível em: http://www.planalto.gov.br/ccivil_03/_Ato2019-2022/2019/Lei/L13840.htm

25 Peters MDJ, Godfrey C, Mclnerney P, Baldini Soares C, Khalil H, Parker D. Capítulo 11: Avaliações de escopo. Em: Aromataris E, Munn Z (Editores). Manual do Revisor do Instituto Joanna Briggs. Instituto Joanna Briggs, 2017. Disponível em https://reviewersmanual.joannabriggs.org/

26 Arksey H, O'Malley L. Scoping studies: towards a methodological framework. International Journal of Social Research Methodology. [Internet] 2005 [acesso em 20 ago 2020]; 8:19-32. Disponível em: doi:org/10.1080/1364557032000119616.

27 Levac D, Wishart L, Missiuna C, Wright V: The application of motor learning strategies within functionally based interventions for children with neuromotor conditions. Peds Phys Ther. [Internet] 2009 [acesso em 20 ago 2020]; 21: 345-355.

Disponivel

em: https://implementationscience.biomedcentral.com/articles/10.1186/1748-59085-69.

28 Virkkunen J, Newham DS. O Laboratório de Mudança: uma ferramenta de desenvolvimento colaborativo para o trabalho e a educação. Belo Horizonte: Fabrefactum, 2015.

29 Miguel AQC, Madruga CS, Cogo-Moreira $H$, et al. Sociodemographic Characteristics, Patterns of Crack Use, Concomitant Substance Use Disorders, and Psychiatric Symptomatology in Treatment-Seeking CrackDependent Individuals in Brazil. J Psychoactive Drugs. 2018;50(4):367-372. doi:10.1080/02791072.2018.1436729 
30 Navarro-Lashayas MA, Eiroa-Orosa FJ. Substance use and psychological distress is related with accommodation status among homeless immigrants. American Journal of Orthopsychiatry. 2017; 87(1), 2333. https://doi.org/10.1037/ort0000213

31 Halpern SC, Scherer JN, Roglio V, Faller S, Sordi A, Ornell F. Vulnerabilidades clínicas e sociais em usuários de crack de acordo com a situação de moradia: um estudo multicêntrico de seis capitais brasileiras. Cad. Saúde Pública [Internet]. 2017 [cited 2020 Oct 15] ; 33( 6 ): e00037517. Disponivel em: http://www.scielo.br/scielo.php?script=sci_arttext\&pid=S0102$311 \times 2017000605002 \& \operatorname{lng}=$ en

32 Mabhala MA, Yohannes A, Griffith M. Social conditions of becoming homelessness: qualitative analysis of life stories of homeless peoples. Int $\mathrm{J}$ Equity Health [Internet] 2017 [cited 2020 Oct 15]; Disponivel em: https://doi.org/10.1186/s12939-017-0646-3

33 Vernaglia TVC, Vieira RAMS, Cruz MS. Usuários de crack em situação de rua - características de gênero. Ciênc. saúde coletiva [Internet]. 2015 [cited 2020 Oct 15]; 20( 6 ): 1851-1859. Disponível em: http://www.scielo.br/scielo.php?script=sci_arttext\&pid=S1413-

$81232015000601851 \& \operatorname{lng}=$ en

34 Hungaro AA, Gavioli A, Christóphoro R, Marangoni SR, Altrão RF, Rodrigues $A L$ et al . Pessoas em situação de rua: caracterização e contextualização por pesquisa censitária. Rev. Bras. Enferm. [Internet]. 2020 [citado em 2020

Oct 15]; 73(5): Disponível em:

http://www.scielo.br/scielo.php?script=sci_arttext\&pid=S0034-

$71672020000500163 \& \operatorname{lng}=$ en

35 Raupp L, Adorno RCF. Territórios psicotrópicos na região central da cidade de Porto Alegre, RS, Brasil. Saude soc. [Internet]. 2015 [citado em 2020 Oct 15];24(3):803-815. Disponível em: http://www.scielo.br/scielo.php?script=sci_arttext\&pid=S0104$12902015000300803 \& \operatorname{lng}=e n$ 
36 Barata RB, Carneiro Junior N, Ribeiro MCSA, Silveira C. Desigualdade social em saúde na população em situação de rua na cidade de São Paulo. Saude soc. [Internet]. 2015 [citado em 2020 Oct 15] ; 24( Suppl 1): 219-232. Disponivel em: http://www.scielo.br/scielo.php?script=sci_arttext\&pid=S0104$12902015000500219 \& \operatorname{lng}=$ en

37 Matoso LM, Silva JS, Nascimento B, Lopes MM. Redução de riscos e danos: ações em saúde com pessoas em situação de rua no interior nordestino. RCS [Internet]. 2019 [citado 15 out 2020];19(37):183-8. Disponível em: https://www.revistas.unijui.edu.br/index.php/contextoesaude/article/view/8109

38 Silva NG, Barros S, Azevedo FC, Batista LB, Policarpo VC. O quesito raça/cor nos estudos de caracterização de usuários de Centro de Atenção Psicossocial. Saúde e Sociedade [Internet] 2017 [citado em 18 set 2020]; 26(1); Disponível em: https://www.scielosp.org/article/sausoc/2017.v26n1/100114/ 


\section{APÊNDICES}

Apêndice A - Instrumento de extração de dados

\begin{tabular}{|c|c|c|c|c|}
\hline \multicolumn{4}{|c|}{ INSTRUMENTO DE EXTRAÇÃO DE DADOS } & ANÁLISE \\
\hline \multirow{4}{*}{ 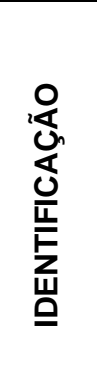 } & \multicolumn{4}{|l|}{ Título: } \\
\hline & \multicolumn{4}{|l|}{ Autores: } \\
\hline & \multicolumn{2}{|l|}{ Ano de Publicação } & \multicolumn{2}{|c|}{ País de origem: } \\
\hline & \multicolumn{2}{|l|}{ Base de dados: } & \multicolumn{2}{|c|}{ Descritores: } \\
\hline \multirow{4}{*}{ 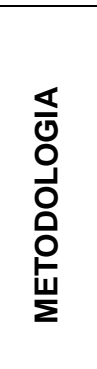 } & \multicolumn{4}{|c|}{ Metodologia de estudo: } \\
\hline & \multicolumn{4}{|l|}{ Método: } \\
\hline & \multicolumn{4}{|l|}{ Objetivo: } \\
\hline & População: & Conceito: & Conte & \\
\hline \multirow{4}{*}{ 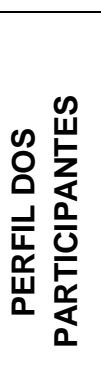 } & \multicolumn{2}{|l|}{ Raça: } & \multicolumn{2}{|c|}{ Idade: } \\
\hline & \multicolumn{4}{|l|}{ Gênero: } \\
\hline & \multicolumn{2}{|l|}{ Estado civil: } & \multicolumn{2}{|c|}{ Escolaridade: } \\
\hline & \multicolumn{2}{|l|}{ Ocupação: } & & \\
\hline \multirow{3}{*}{ 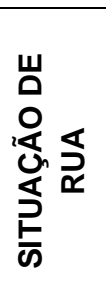 } & \multicolumn{4}{|c|}{ Causas da permanência na rua: } \\
\hline & \multicolumn{4}{|c|}{ Tempo médio de permanência na rua: } \\
\hline & \multicolumn{4}{|c|}{ Dispositivos de auxílio utilizados: } \\
\hline \multirow{3}{*}{ 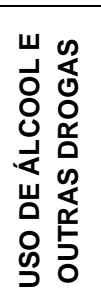 } & \multicolumn{4}{|c|}{ Drogas mais utilizadas: } \\
\hline & \multicolumn{4}{|c|}{ Padrão de uso médio: } \\
\hline & \multicolumn{4}{|c|}{ Programas e dispositivos de saúde utilizados: } \\
\hline
\end{tabular}


Apêndice B - Resultado de extração de dados

\begin{tabular}{|c|c|c|c|}
\hline \multicolumn{4}{|c|}{ INSTRUMENTO DE EXTRAÇÃO DE DADOS } \\
\hline \multirow{4}{*}{ 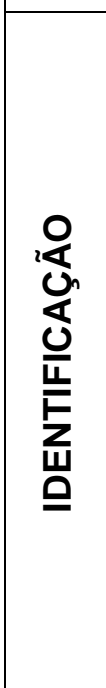 } & \multicolumn{3}{|c|}{$\begin{array}{l}\text { Título: Sociodemographic Characteristics, Patterns of Crack Use, } \\
\text { Concomitant Substance Use Disorders, and Psychiatric Symptomatology in } \\
\text { Treatment-Seeking Crack-Dependent Individuals in Brazil }\end{array}$} \\
\hline & \multicolumn{3}{|c|}{ Autores: Miguel AQC et al. } \\
\hline & \multicolumn{2}{|c|}{ Ano de Publicação: 2018} & País de origem: Brasil \\
\hline & \multicolumn{2}{|c|}{ Base de dados: PUBMED } & $\begin{array}{l}\text { Descritores: Crack } \\
\text { dependence; ambulatory } \\
\text { treatment; profile features; } \\
\text { Brazil }\end{array}$ \\
\hline \multirow{4}{*}{ 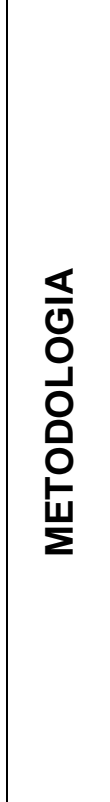 } & \multicolumn{3}{|c|}{ Metodologia de estudo: Misto } \\
\hline & \multicolumn{3}{|c|}{$\begin{array}{l}\text { Método: Entrevistas individuais de até } 90 \text { min. com perguntas relacionadas } \\
\text { às características sociodemográficas, histórico/padrão de uso de drogas e } \\
\text { histórico de tratamento. }\end{array}$} \\
\hline & \multicolumn{3}{|c|}{$\begin{array}{l}\text { Objetivo: Fornecer conhecimentos adicionais sobre as características } \\
\text { sociodemográficas, padrões de uso de crack, transtornos por uso de } \\
\text { substâncias concomitantes e sintomatologia psiquiátrica em dependentes de } \\
\text { crack que relatam uso recente de crack e procuram tratamento ambulatorial } \\
\text { no Brasil. }\end{array}$} \\
\hline & $\begin{array}{l}\text { População: } 65 \\
\text { usuários de crack }\end{array}$ & \begin{tabular}{|l|} 
Conceito: \\
Características \\
sociodemográficas
\end{tabular} & $\begin{array}{l}\text { Contexto: Tratamento } \\
\text { ambulatorial - Vila Maria - } \\
\text { São Paulo/SP }\end{array}$ \\
\hline \multirow{3}{*}{ 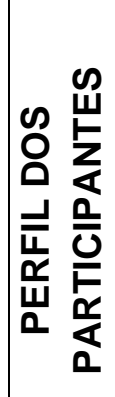 } & \multicolumn{2}{|c|}{ Raça: Dado não informado } & Idade: 35 anos (média) \\
\hline & \multicolumn{3}{|c|}{ Gênero: Homens (87.7\% - 57 participantes) } \\
\hline & \multicolumn{2}{|c|}{$\begin{array}{l}\text { Estado civil: Solteiros }(69.2 \% \text { - } 45 \\
\text { participantes) }\end{array}$} & $\begin{array}{l}\text { Escolaridade: Ensino } \\
\text { fundamental }(35.4 \%-23 \\
\text { participantes) }\end{array}$ \\
\hline
\end{tabular}




\begin{tabular}{|c|c|}
\hline & Ocupação: Desempregados (83.1\% - 54 participantes) \\
\hline \multirow{3}{*}{ 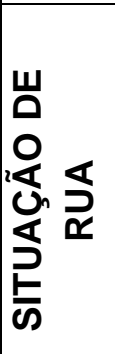 } & $\begin{array}{l}\text { Causas da permanência na rua: } 64.6 \% \text { (42 participantes) referem dormir } \\
\text { na rua por conta do uso de crack }\end{array}$ \\
\hline & Tempo médio de permanência na rua: Dado não informado \\
\hline & Dispositivos de auxílio utilizados: Dado não informado \\
\hline \multirow{3}{*}{ 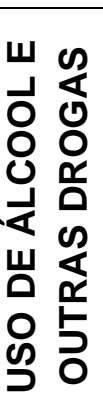 } & $\begin{array}{l}\text { Drogas mais utilizadas: Além do Crack é observado pelos participantes } \\
\text { forte uso de tabaco }(90.8 \%-59) \text {, alcool }(66.1 \% \text { - } 43) \text { e maconha }(12,3 \%-8) \text {. }\end{array}$ \\
\hline & Padrão de uso médio: Aproximadamente 12 pedras/dia \\
\hline & $\begin{array}{l}\text { Programas e dispositivos de saúde em uso ou já utilizados: Tratamento } \\
\text { ambulatorial, reuniões de autoajuda, internação }\end{array}$ \\
\hline \multicolumn{2}{|r|}{$\begin{array}{l}\text { Outras informações relevantes: Forte associação entre marginalização e uso de } \\
\text { crack; Uso mais frequente entre pessoas em vulnerabilidade social; A idade média } \\
\text { de início do uso de crack foi de } 22 \text { anos, e a duração média do uso contínuo de } \\
\text { crack foi de } 12 \text { anos; Depressão e sintomas de ansiedade são as comorbidades } \\
\text { psiquiátricas mais vivenciadas; }\end{array}$} \\
\hline
\end{tabular}




\begin{tabular}{|c|c|c|c|c|}
\hline \multicolumn{4}{|c|}{ INSTRUMENTO DE EXTRAÇÃO DE DADOS } & A2 \\
\hline \multirow{4}{*}{ 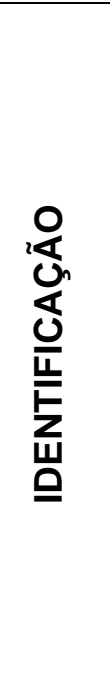 } & \multicolumn{4}{|c|}{$\begin{array}{l}\text { Título: Substance Use and Psychological Distress Is Related With } \\
\text { Accommodation Status Among Homeless Immigrants }\end{array}$} \\
\hline & \multicolumn{4}{|c|}{ Autores: Navarro-Lashayas MA, Eiroa-Orosa FJ } \\
\hline & \multicolumn{2}{|c|}{ Ano de Publicação: 2017} & \multicolumn{2}{|c|}{ País de origem: Espanha } \\
\hline & \multicolumn{2}{|c|}{ Base de dados: PUBMED } & \multicolumn{2}{|c|}{$\begin{array}{l}\text { Descritores: } \\
\text { Homelessness, alcohol, } \\
\text { drugs, stressful life events, } \\
\text { accommodation status, } \\
\text { mixed methods }\end{array}$} \\
\hline \multirow{4}{*}{ 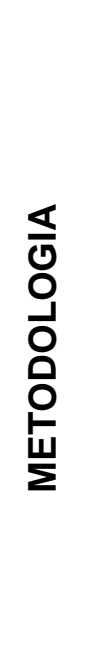 } & \multicolumn{4}{|c|}{ Metodologia de estudo: Misto - quantitativo e qualitativo } \\
\hline & \multicolumn{4}{|c|}{$\begin{array}{l}\text { Método: Grupos focais, entrevistas estruturadas e questionários } \\
\text { psicométricos; }\end{array}$} \\
\hline & \multicolumn{4}{|c|}{$\begin{array}{l}\text { Objetivo: Analisar como o uso abusivo de substancias, sofrimento psíquico } \\
\text { e experiencias estressantes podem influenciar na situação de rua e como os } \\
\text { usuários percebem essa influência em suas vidas. }\end{array}$} \\
\hline & $\begin{array}{l}\text { População: } 107 \\
\text { imigrantes em } \\
\text { situação de rua }\end{array}$ & $\begin{array}{l}\text { Conceito: Uso de } \\
\text { substâncias }\end{array}$ & $\begin{array}{l}\text { Contexto: } \\
\text { rua }\end{array}$ & Situação de \\
\hline \multirow{3}{*}{ 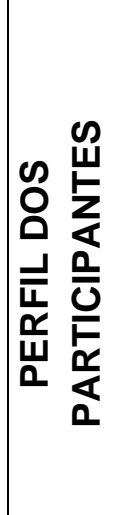 } & \multicolumn{2}{|c|}{ Raça: Dado não informado } & \multicolumn{2}{|c|}{ Idade: 32 anos (média) } \\
\hline & \multicolumn{4}{|c|}{ Gênero: Dado não informado } \\
\hline & \multicolumn{2}{|c|}{ Estado civil: Solteiros (83.3\%) } & \multicolumn{2}{|c|}{$\begin{array}{l}\text { Escolaridade: Ensino } \\
\text { fundamental (média); } \\
\text { Ensino Médio (entre os } \\
\text { lotados em casas de } \\
\text { acolhimento) }\end{array}$} \\
\hline
\end{tabular}




\begin{tabular}{|c|c|}
\hline & Ocupação: Empregos temporários e de baixa remuneração; \\
\hline \multirow{3}{*}{ 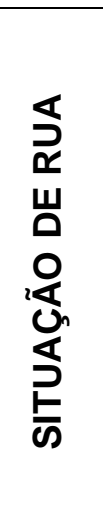 } & $\begin{array}{l}\text { Causas da permanência na rua: Morte de um ente querido, término de } \\
\text { relacionamento, problemas relacionados a emprego, binge drinking e uso de } \\
\text { drogas; }\end{array}$ \\
\hline & Tempo médio de permanência na rua: 13 meses \\
\hline & $\begin{array}{l}\text { Dispositivos de auxílio utilizados: } 24.3 \% \text { recebiam auxílio social (não } \\
\text { especificado); Os autores referem que os requerentes de asilo participantes } \\
\text { do estudo não contavam com nenhum suporte de auxílio; }\end{array}$ \\
\hline \multirow{3}{*}{ 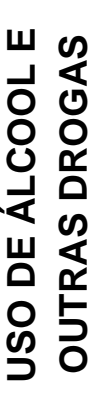 } & Drogas mais utilizadas: Alcool, Haxixe \\
\hline & $\begin{array}{l}\text { Padrão de uso médio: Alcool (diariamente), Haxixe ( } 3 \text { ou mais dias por } \\
\text { semana) }\end{array}$ \\
\hline & $\begin{array}{l}\text { Programas e dispositivos de saúde em uso ou já utilizados: Dado não } \\
\text { informado }\end{array}$ \\
\hline \multicolumn{2}{|r|}{$\begin{array}{l}\text { Outras informações relevantes: Maioria dos participantes imigrou da África (região do } \\
\text { Magrebe e África subsaariana); } 21 \% \text { estava em situação legal para viver e trabalhar na } \\
\text { Espanha; } 22 \% \text { já utilizavam drogas antes de ingressar na situação de rua; } 35 \% \text { relata } \\
\text { abuso de álcool após ingressar na situação de rua; } 22 \% \text { afirma que já utilizava drogas } \\
\text { antes de ingressar na situação de rua; Participantes relatam que o uso de álcool é uma } \\
\text { forma de socialização; "criação" de uma identidade para viver nas ruas; }\end{array}$} \\
\hline
\end{tabular}




\begin{tabular}{|c|c|c|c|c|}
\hline \multicolumn{4}{|c|}{ INSTRUMENTO DE EXTRAÇÃO DE DADOS } & A3 \\
\hline \multirow{4}{*}{ 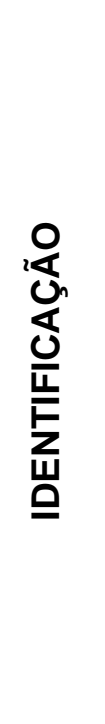 } & \multicolumn{4}{|c|}{$\begin{array}{l}\text { Título: Vulnerabilidades clínicas e sociais em usuários de crack de } \\
\text { acordo com a situação de moradia: um estudo multicêntrico em seis } \\
\text { capitais brasileiras }\end{array}$} \\
\hline & \multicolumn{4}{|c|}{ Autores: Halpern SC et al. } \\
\hline & \multicolumn{2}{|c|}{ Ano de Publicação: 2017} & \multicolumn{2}{|c|}{ País de origem: Brasil } \\
\hline & \multicolumn{2}{|c|}{ Base de dados: PUBMED } & \multicolumn{2}{|c|}{$\begin{array}{l}\text { Descritores: Transtornos } \\
\text { Relacionados ao Uso de } \\
\text { Substâncias; Crack; Pessoas } \\
\text { em Situação de Rua; } \\
\text { Vulnerabilidade em Saúde; } \\
\text { Vulnerabilidade Social }\end{array}$} \\
\hline \multirow{4}{*}{ 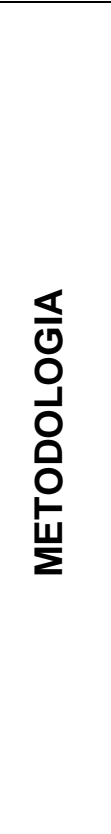 } & \multicolumn{4}{|c|}{$\begin{array}{l}\text { Metodologia de estudo: Estudo transversal de abordagem } \\
\text { quantitativa }\end{array}$} \\
\hline & \multicolumn{4}{|c|}{ Método: Entrevistas semiestruturadas } \\
\hline & \multicolumn{4}{|c|}{$\begin{array}{l}\text { Objetivo: Avaliar a gravidade do uso de substâncias psicoativas, } \\
\text { situações de violência, saúde física e emocional de usuários de crack } \\
\text { que buscam atendimento em Centros de Atenção Psicossocial para } \\
\text { Álcool e Drogas (CAPSad), em relação ao status de moradia. }\end{array}$} \\
\hline & $\begin{array}{l}\text { População: } 564 \\
\text { participantes (47.1\% - } \\
266 \text { participantes } \\
\text { estavam ou já } \\
\text { estiveram em } \\
\text { situação de rua) }\end{array}$ & $\begin{array}{l}\text { Conceito: Uso } \\
\text { de crack }\end{array}$ & Conte & tus de moradia \\
\hline \multirow{4}{*}{ 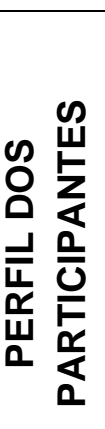 } & \multicolumn{2}{|c|}{ Raça: Parda $(34.6 \%$ - 92$)$} & \multicolumn{2}{|c|}{ Idade: 32 anos (média) } \\
\hline & \multicolumn{4}{|c|}{ Gênero: Masculino $(81.5 \%-216)$} \\
\hline & \multicolumn{2}{|c|}{ Estado civil: Solteiro $(38.9 \%-103)$} & \multicolumn{2}{|c|}{$\begin{array}{l}\text { Escolaridade: Fundamental } \\
(50.4 \%-134)\end{array}$} \\
\hline & \multicolumn{4}{|c|}{ Ocupação: Desempregado/Fora do mercado de trabalho $(82 \%$ - 218) } \\
\hline
\end{tabular}




\begin{tabular}{|c|c|}
\hline \multirow{3}{*}{ 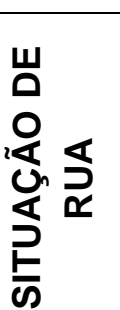 } & $\begin{array}{l}\text { Causas da permanência na rua: Uso de drogas; sucessivas perdas e } \\
\text { fracassos pessoais }\end{array}$ \\
\hline & Tempo médio de permanência na rua: Dado não informado \\
\hline & Dispositivos de auxílio utilizados: Dado não informado \\
\hline \multirow{3}{*}{ 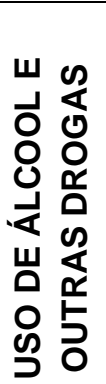 } & Drogas mais utilizadas: Crack e álcool \\
\hline & Padrão de uso médio: Dado não informado \\
\hline & $\begin{array}{l}\text { Programas e dispositivos de saúde em uso ou já utilizados: } \\
\text { CAPSad }\end{array}$ \\
\hline \multicolumn{2}{|c|}{$\begin{array}{l}\text { Outras informações relevantes: Grande vulnerabilidade social, falta de } \\
\text { programas de auxílio social; Estudo traz dados sobre violência; }\end{array}$} \\
\hline
\end{tabular}




\begin{tabular}{|c|c|c|c|c|}
\hline \multicolumn{4}{|c|}{ INSTRUMENTO DE EXTRAÇÃO DE DADOS } & A4 \\
\hline \multirow{4}{*}{ 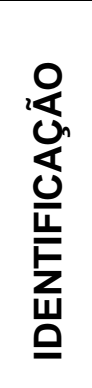 } & \multicolumn{4}{|c|}{$\begin{array}{l}\text { Título: Social conditions of becoming homelessness: qualitative analysis of life } \\
\text { stories of homeless peoples }\end{array}$} \\
\hline & \multicolumn{4}{|c|}{ Autores: Mabhala MA, Yohannes A, Griffth M } \\
\hline & \multicolumn{2}{|c|}{ Ano de Publicação: 2017} & \multicolumn{2}{|c|}{ País de origem: Inglaterra } \\
\hline & \multicolumn{2}{|c|}{ Base de dados: PUBMED } & Descritor & \\
\hline \multirow{4}{*}{ 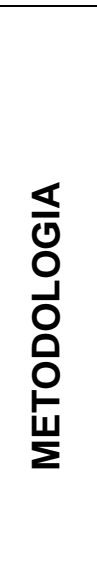 } & \multicolumn{4}{|c|}{ Metodologia de estudo: Qualitativa } \\
\hline & \multicolumn{4}{|c|}{ Método: Entrevistas semi-estruturadas } \\
\hline & \multicolumn{4}{|c|}{$\begin{array}{l}\text { Objetivo: Examinar as histórias de moradores de rua para obter uma } \\
\text { compreensão do social condições em que ocorre a falta de moradia, a fim de } \\
\text { propor uma explicação teórica para ela }\end{array}$} \\
\hline & $\begin{array}{l}\text { População: } \\
\text { Pessoas em } \\
\text { situação de rua }\end{array}$ & $\begin{array}{l}\text { Conceito: } \\
\text { Comportamento } \\
\text { mal adaptativo }\end{array}$ & Contexto & \\
\hline \multirow{4}{*}{ 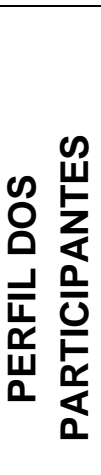 } & \multicolumn{2}{|c|}{ Raça: Dado não informado } & \multicolumn{2}{|c|}{ Idade: 38.6 anos } \\
\hline & \multicolumn{4}{|c|}{ Gênero: Masculino (22 participantes) } \\
\hline & \multicolumn{2}{|c|}{$\begin{array}{l}\text { Estado civil: Maioria dos participantes } \\
\text { é divorciada }\end{array}$} & \multicolumn{2}{|c|}{$\begin{array}{l}\text { Escolaridade: Ensino médio } \\
\text { incompleto }\end{array}$} \\
\hline & \multicolumn{4}{|c|}{ Ocupação: Subemprego ou desempregado } \\
\hline \multirow{3}{*}{ 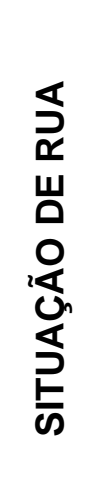 } & \multicolumn{4}{|c|}{$\begin{array}{l}\text { Causas da permanência na rua: Uso excessivo de álcool e outras drogas, } \\
\text { comportamento desajustado e problemas com autoridades }\end{array}$} \\
\hline & \multicolumn{4}{|c|}{ Tempo médio de permanência na rua: Dado não informado. } \\
\hline & \multicolumn{4}{|c|}{ Dispositivos de auxílio utilizados: Dado não informado. } \\
\hline
\end{tabular}




\begin{tabular}{|c|c|}
\hline \multirow{3}{*}{ 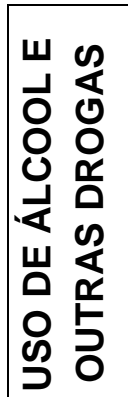 } & $\begin{array}{l}\text { Drogas mais utilizadas: Alcool amplamente utilizado; alguns relatos sobre uso } \\
\text { de maconha e cocaína. }\end{array}$ \\
\hline & Padrão de uso médio: Dado não informado \\
\hline & Programas e dispositivos de saúde utilizados: Dado não informado. \\
\hline \multicolumn{2}{|r|}{$\begin{array}{l}\text { Outras informações relevantes: Análise dos relatos revela que a situação de rua está } \\
\text { atrelada a uma série de incidentes ocorridos desde a infância dos participantes; A } \\
\text { maioria dos participantes passou por uma infância e adolescência conturbada; Muitos } \\
\text { foram expostos a diversos tipos de violência (física, sexual e verbal); }\end{array}$} \\
\hline
\end{tabular}




\begin{tabular}{|c|c|c|c|}
\hline \multicolumn{3}{|c|}{ INSTRUMENTO DE EXTRAÇÃO DE DADOS } & A5 \\
\hline \multirow{4}{*}{ 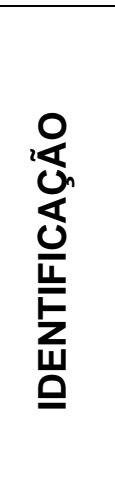 } & \multicolumn{3}{|c|}{ Título: Usuários de crack em situação de rua - características de gênero } \\
\hline & \multicolumn{3}{|c|}{ Autores: Vernaglia TVC, Vieira RAMS, Cruz MS } \\
\hline & \multicolumn{2}{|c|}{ Ano de Publicação: 2015} & País de origem: Brasil \\
\hline & \multicolumn{2}{|c|}{ Base de dados: PUBMED } & $\begin{array}{l}\text { Descritores: Sem-teto, } \\
\text { Crack cocaína, Relações de } \\
\text { Gênero }\end{array}$ \\
\hline \multirow{4}{*}{ 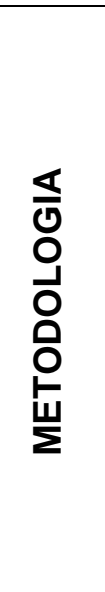 } & \multicolumn{3}{|c|}{ Metodologia de estudo: Qualitativo, descritivo, exploratório } \\
\hline & \multicolumn{3}{|c|}{ Método: Grupo focal e entrevista individual. } \\
\hline & \multicolumn{3}{|c|}{$\begin{array}{l}\text { Objetivo: Identificar como se constituem as relações de gênero no cotidiano } \\
\text { dos usuários de crack; e analisar a dinâmica que permeia a construção destas } \\
\text { relações que envolvem troca e poder. }\end{array}$} \\
\hline & $\begin{array}{l}\text { População: } \\
\text { Usuários de crack } \\
\text { (31) }\end{array}$ & $\begin{array}{l}\text { Conceito: Uso de crack } \\
\text { e gênero }\end{array}$ & Contexto: Situação de rua \\
\hline \multirow{4}{*}{ 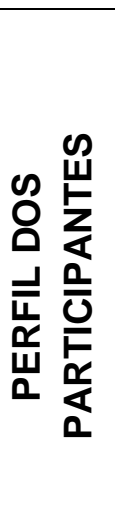 } & \multicolumn{2}{|l|}{ Raça: Parda (20) } & $\begin{array}{l}\text { Idade: Maiores de } 18 \text { anos; } \\
\text { Idade média não } \\
\text { especificada. }\end{array}$ \\
\hline & \multicolumn{3}{|c|}{ Gênero: Maioria dos participantes era do sexo feminino (18) } \\
\hline & \multicolumn{2}{|c|}{ Estado civil: Solteiro (22) } & $\begin{array}{l}\text { Escolaridade: Ensino } \\
\text { fundamental incompleto (25) }\end{array}$ \\
\hline & \multicolumn{3}{|c|}{ Ocupação: Trabalho informal (22) } \\
\hline \multirow{3}{*}{ 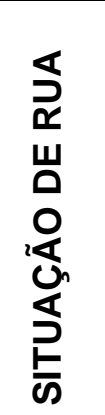 } & \multicolumn{3}{|c|}{ Causas da permanência na rua: Dado não informado. } \\
\hline & \multicolumn{3}{|c|}{ Tempo médio de permanência na rua: Dado não informado. } \\
\hline & \multicolumn{3}{|c|}{$\begin{array}{l}\text { Dispositivos de auxílio utilizados: Os participantes relatam não receber } \\
\text { qualquer auxílio do governo (28). }\end{array}$} \\
\hline
\end{tabular}




\begin{tabular}{|c|c|}
\hline \multirow{3}{*}{ 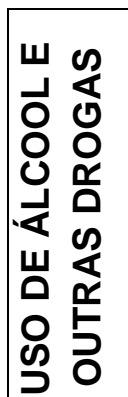 } & Drogas mais utilizadas: Crack \\
\hline & Padrão de uso médio: Dado não informado. \\
\hline & $\begin{array}{l}\text { Programas e dispositivos de saúde utilizados: Clínica da família/UBS da } \\
\text { comunidade }\end{array}$ \\
\hline \multicolumn{2}{|r|}{$\begin{array}{l}\text { Outras informações relevantes: Destaca-se o vínculo entre os usuários; Prostituição } \\
\text { forma de sobrevivência em ambos dos gêneros; Relação entre maternidade e } \\
\text { posição de superioridade; }\end{array}$} \\
\hline
\end{tabular}




\begin{tabular}{|c|c|c|c|c|}
\hline & \multicolumn{3}{|c|}{ INSTRUMENTO DE EXTRAÇÃO DE DADOS } & A6 \\
\hline \multirow{4}{*}{ 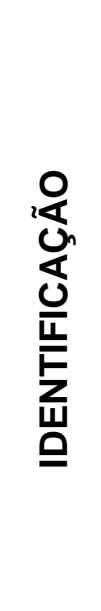 } & \multicolumn{4}{|c|}{$\begin{array}{l}\text { Título: Pessoas em situação de rua: caracterização e contextualização por } \\
\text { pesquisa censitária }\end{array}$} \\
\hline & \multicolumn{4}{|c|}{$\begin{array}{l}\text { Autores: Húngaro AA, Gavioli A, Christóphoro R, Marangoni SR, Altrão RF, } \\
\text { Rodrigues AL, et al }\end{array}$} \\
\hline & \multicolumn{2}{|c|}{ Ano de Publicação: 2020} & Paí & \\
\hline & \multicolumn{2}{|c|}{ Base de dados: LILACS/BVS } & $\begin{array}{l}\text { Des } \\
\text { de } \\
\text { Vull } \\
\text { Enf }\end{array}$ & $\begin{array}{l}\text { S em Situação } \\
\text { ulações } \\
\text { lícitas; } \\
\text { de Pública }\end{array}$ \\
\hline \multirow{4}{*}{ 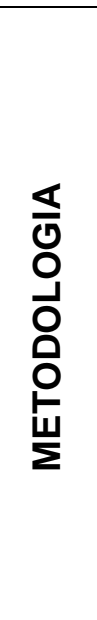 } & \multicolumn{4}{|c|}{ Metodologia de estudo: Quantitativa, descritiva. } \\
\hline & \multicolumn{4}{|c|}{$\begin{array}{l}\text { Método: Estudo seccional do tipo censitário, através da utilização de } \\
\text { questionário estruturado. }\end{array}$} \\
\hline & \multicolumn{4}{|c|}{$\begin{array}{l}\text { Objetivo: Analisar características de moradores de rua em um município de } \\
\text { médio porte da região norte do estado do Paraná, de } 2015 \text { a 2018, e fatores } \\
\text { associados à vida nas ruas. }\end{array}$} \\
\hline & $\begin{array}{l}\text { População: Pessoas } \\
\text { em situação de rua }\end{array}$ & $\begin{array}{l}\text { Conceito: Uso } \\
\text { de álcool e } \\
\text { outras drogas }\end{array}$ & Cor & e rua \\
\hline \multirow{4}{*}{ 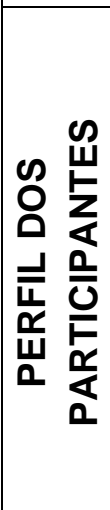 } & \multicolumn{2}{|c|}{ Raça: Parda (52.2\% - 366) } & \multicolumn{2}{|c|}{ Idade: 37,7 anos } \\
\hline & \multicolumn{4}{|c|}{ Gênero: Masculino (90,7\% - 635 participantes) } \\
\hline & \multicolumn{2}{|c|}{ Estado civil: Solteiro (58.5\%) } & \multicolumn{2}{|c|}{$\begin{array}{l}\text { Escolaridade: Analfabetismo ou } \\
\text { Ensino fundamental incompleto } \\
(54.2 \%)\end{array}$} \\
\hline & \multicolumn{4}{|c|}{$\begin{array}{l}\text { Ocupação: Mendicância, cuidador de carros/flanelinha, coleta de recicláveis, } \\
\text { servente de pedreiro e prostituição. }\end{array}$} \\
\hline \multirow{3}{*}{ 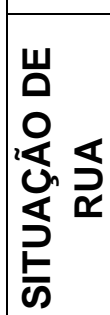 } & \multicolumn{4}{|c|}{$\begin{array}{l}\text { Causas da permanência na rua: Uso de drogas }(47,2 \%) \text {, desentendimentos } \\
\text { familiares }(38,9 \%) \text { e desemprego }(25,5 \%)\end{array}$} \\
\hline & \multicolumn{4}{|c|}{ Tempo médio de permanência na rua: 5,39 anos } \\
\hline & \multicolumn{4}{|c|}{ Dispositivos de auxílio utilizados: Defensoria pública do Estado da Bahia } \\
\hline
\end{tabular}




\begin{tabular}{|c|c|}
\hline \multirow{3}{*}{ 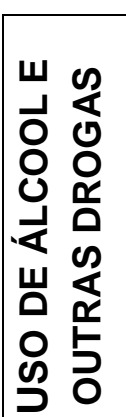 } & $\begin{array}{l}\text { Drogas mais utilizadas: Tabaco }(84,6 \%) \text {, álcool }(84.7 \%) \text {, maconha }(67.9 \%) \text {, } \\
\text { crack }(63,9 \%) \text {, cocaína ( } 44.1 \%) \text { e inalantes }(40.1 \%)\end{array}$ \\
\hline & Padrão de uso médio: Dado não informado \\
\hline & $\begin{array}{l}\text { Programas e dispositivos de saúde utilizados: UBS }(65,3 \%) \text { e consultório de } \\
\text { rua }(3,3 \%)\end{array}$ \\
\hline \multicolumn{2}{|r|}{$\begin{array}{l}\text { Outras informações relevantes: Pesquisa realizada de } 2015 \text { a } 2018 \text { na cidade de } \\
\text { Maringá/PR, }\end{array}$} \\
\hline
\end{tabular}




\begin{tabular}{|c|c|c|c|c|}
\hline \multicolumn{4}{|c|}{ INSTRUMENTO DE EXTRAÇÃO DE DADOS } & A7 \\
\hline \multirow{4}{*}{ 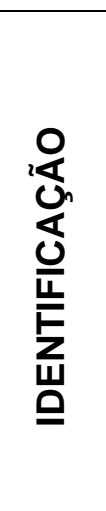 } & \multicolumn{4}{|c|}{$\begin{array}{l}\text { Título: Territórios psicotrópicos na região central da cidade de Porto } \\
\text { Alegre, RS, Brasil }\end{array}$} \\
\hline & \multicolumn{4}{|c|}{ Autores: Raupp L, Adorno RCF } \\
\hline & \multicolumn{2}{|c|}{ Ano de Publicação: 2015} & \multicolumn{2}{|c|}{ País de origem: Brasil } \\
\hline & \multicolumn{2}{|c|}{ Base de dados: LILACS/BVS } & \multicolumn{2}{|c|}{$\begin{array}{l}\text { Descritores: Crack; } \\
\text { Etnografia; Saúde } \\
\text { Pública }\end{array}$} \\
\hline \multirow{4}{*}{ 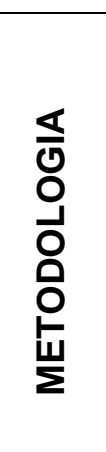 } & \multicolumn{4}{|c|}{ Metodologia de estudo: Qualitativa } \\
\hline & \multicolumn{4}{|l|}{ Método: Etnográfico } \\
\hline & \multicolumn{4}{|c|}{$\begin{array}{l}\text { Objetivo: Questão dos usos e circulação do crack na região central da } \\
\text { cidade de Porto Alegre. }\end{array}$} \\
\hline & $\begin{array}{l}\text { População: Pessoas } \\
\text { em situação de rua }\end{array}$ & $\begin{array}{l}\text { Conceito: Uso de } \\
\text { crack }\end{array}$ & \multicolumn{2}{|c|}{$\begin{array}{l}\text { Contexto: Situação de } \\
\text { rua }\end{array}$} \\
\hline \multirow{4}{*}{ 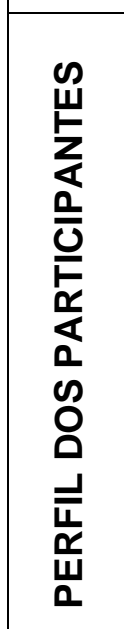 } & \multicolumn{2}{|c|}{ Raça: Dado não informado } & \multicolumn{2}{|c|}{$\begin{array}{l}\text { Idade: Jovens, adultos } \\
\text { e idosos foram } \\
\text { observados }\end{array}$} \\
\hline & \multicolumn{4}{|c|}{ Gênero: Masculino (predominante) } \\
\hline & \multicolumn{2}{|c|}{ Estado civil: Dado não informado } & \multicolumn{2}{|c|}{$\begin{array}{l}\text { Escolaridade: Ensino } \\
\text { fundamental } \\
\text { incompleto }\end{array}$} \\
\hline & \multicolumn{4}{|c|}{$\begin{array}{l}\text { Ocupação: Atividades informais (coleta de recicláveis, engraxate, } \\
\text { guardador de carros, prostituição e mendicância) }\end{array}$} \\
\hline \multirow{3}{*}{ 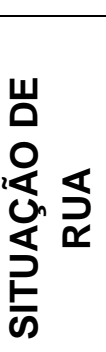 } & \multicolumn{4}{|c|}{ Causas da permanência na rua: Abuso de drogas } \\
\hline & \multicolumn{4}{|c|}{ Tempo médio de permanência na rua: 2 anos (conforme relatos) } \\
\hline & \multicolumn{4}{|c|}{ Dispositivos de auxílio utilizados: Albergue municipal } \\
\hline
\end{tabular}




\begin{tabular}{|c|c|}
\hline \multirow{3}{*}{ 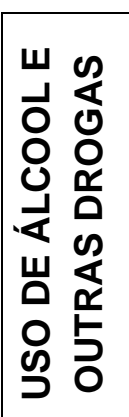 } & $\begin{array}{l}\text { Drogas mais utilizadas: Crack, maconha e solvente (mais jovens); álcool } \\
\text { (mais velhos); }\end{array}$ \\
\hline & $\begin{array}{l}\text { Padrão de uso médio: Questão subjetiva. Em grande maioria, os } \\
\text { entrevistados relataram utilizar crack e outras drogas diariamente. }\end{array}$ \\
\hline & Programas e dispositivos de saúde utilizados: Equipe de rua - ESF \\
\hline \multicolumn{2}{|r|}{$\begin{array}{l}\text { Outras informações relevantes: Os autores ressaltam que mesmo sendo } \\
\text { predominante a presença de homens em situação de rua foi possível observar } \\
\text { também mulheres; a menor quantidade de mulheres encontradas na região do } \\
\text { estudo se dá por muitas usuárias passarem o dia em pontos de prostituição } \\
\text { próximos; Uso compulsivo de crack é observado nos relatos dos participantes; }\end{array}$} \\
\hline
\end{tabular}




\begin{tabular}{|c|c|c|c|}
\hline \multicolumn{3}{|c|}{ INSTRUMENTO DE EXTRAÇÃO DE DADOS } & A8 \\
\hline \multirow{4}{*}{ 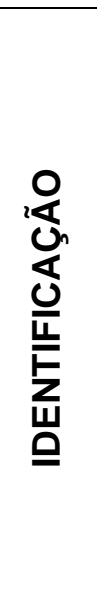 } & \multicolumn{3}{|c|}{$\begin{array}{l}\text { Título: Desigualdade social em saúde na população em situação de rua na } \\
\text { cidade de São Paulo }\end{array}$} \\
\hline & \multicolumn{3}{|c|}{ Autores: Barata RB, Carneiro Júnior N, Ribeiro MCSA, Silveira C. } \\
\hline & \multicolumn{2}{|c|}{ Ano de Publicação: 2015} & País de origem: Brasil \\
\hline & \multicolumn{2}{|c|}{ Base de dados: Google Acadêmico } & $\begin{array}{l}\text { Descritores: População em } \\
\text { Situação de Rua; Condições } \\
\text { de Vida; Condições de } \\
\text { Saúde; Acesso e Serviços de } \\
\text { Saúde }\end{array}$ \\
\hline \multirow{4}{*}{ 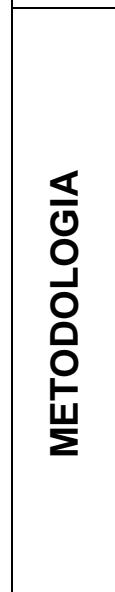 } & \multicolumn{3}{|c|}{ Metodologia de estudo: Quantitativa } \\
\hline & \multicolumn{3}{|l|}{ Método: Entrevis } \\
\hline & \multicolumn{3}{|c|}{$\begin{array}{l}\text { Objetivo: Descrever as características sociodemográficas, o estado de saúde } \\
\text { e o acesso a serviços na população em situação de rua em uma amostra em } \\
\text { três albergues do centro da cidade de São Paulo. }\end{array}$} \\
\hline & $\begin{array}{l}\text { População: } \\
\text { Pessoas em } \\
\text { situação de rua }\end{array}$ & $\begin{array}{l}\text { Conceito: } \\
\text { Vulnerabilidades }\end{array}$ & Contexto: Situação de rua \\
\hline \multirow{4}{*}{ 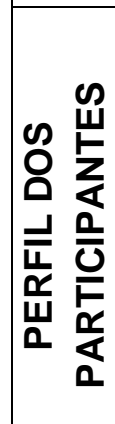 } & \multicolumn{2}{|c|}{ Raça: Não branco (63.7\%) } & Idade: $40-59(59 \%)$ \\
\hline & \multicolumn{3}{|c|}{ Gênero: Masculino (68.1\%) } \\
\hline & \multicolumn{2}{|c|}{ Estado civil: Solteiro $(52,6)$} & $\begin{array}{l}\text { Escolaridade: Ensino } \\
\text { fundamental }(29,9)\end{array}$ \\
\hline & \multicolumn{3}{|c|}{ Ocupação: Trabalho eventual (30.6\%) } \\
\hline \multirow{3}{*}{ 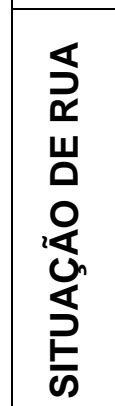 } & \multicolumn{3}{|c|}{$\begin{array}{l}\text { Causas da permanência na rua: Condições financeiras }(62.9 \%) \text { e ausência } \\
\text { de família }(32.3 \%) ;\end{array}$} \\
\hline & \multicolumn{3}{|c|}{ Tempo médio de permanência na rua: $>5$ anos $(33.2 \%)$} \\
\hline & \multicolumn{3}{|c|}{ Dispositivos de auxílio utilizados: Albergue municipal } \\
\hline
\end{tabular}




\begin{tabular}{|c|c|}
\hline \multirow{3}{*}{ 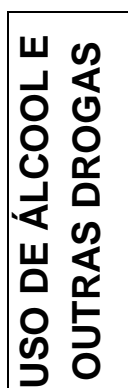 } & $\begin{array}{l}\text { Drogas mais utilizadas: Tabaco (57\%), álcool (34\%), maconha (27.5\%), } \\
\text { cocaína inalada (13.7\%), crack (12,9\%); }\end{array}$ \\
\hline & Padrão de uso médio: Dado subjetivo; \\
\hline & $\begin{array}{l}\text { Programas e dispositivos de saúde utilizados: Centro de saúde }(59.2 \%) \text {, } \\
\text { pronto socorro }(21 \%)\end{array}$ \\
\hline \multicolumn{2}{|r|}{$\begin{array}{l}\text { Outras informações relevantes: } O \text { estudo foi realizado em dois grupos, sendo o } 1^{\circ} \\
\text { em situação de rua que pernoitava em vias públicas e } 2^{\circ} \text { em situação de rua que } \\
\text { pernoitava em albergue; O perfil dos que pernoitam em albergue apresentam uma } \\
\text { serie de diferenças, entre elas o gênero predominante é feminino e idade entre } 20-39 \\
\text { O indicador raça não é muito especifico e contempla apenas respostas branco e não } \\
\text { branco; Sobre educação, } 5.3 \% \text { dos que pernoitam em albergue possuem ensino } \\
\text { superior e estado civil, } 39.4 \% \text { são casados; trabalho informal diz respeito a "bicos"; }\end{array}$} \\
\hline
\end{tabular}




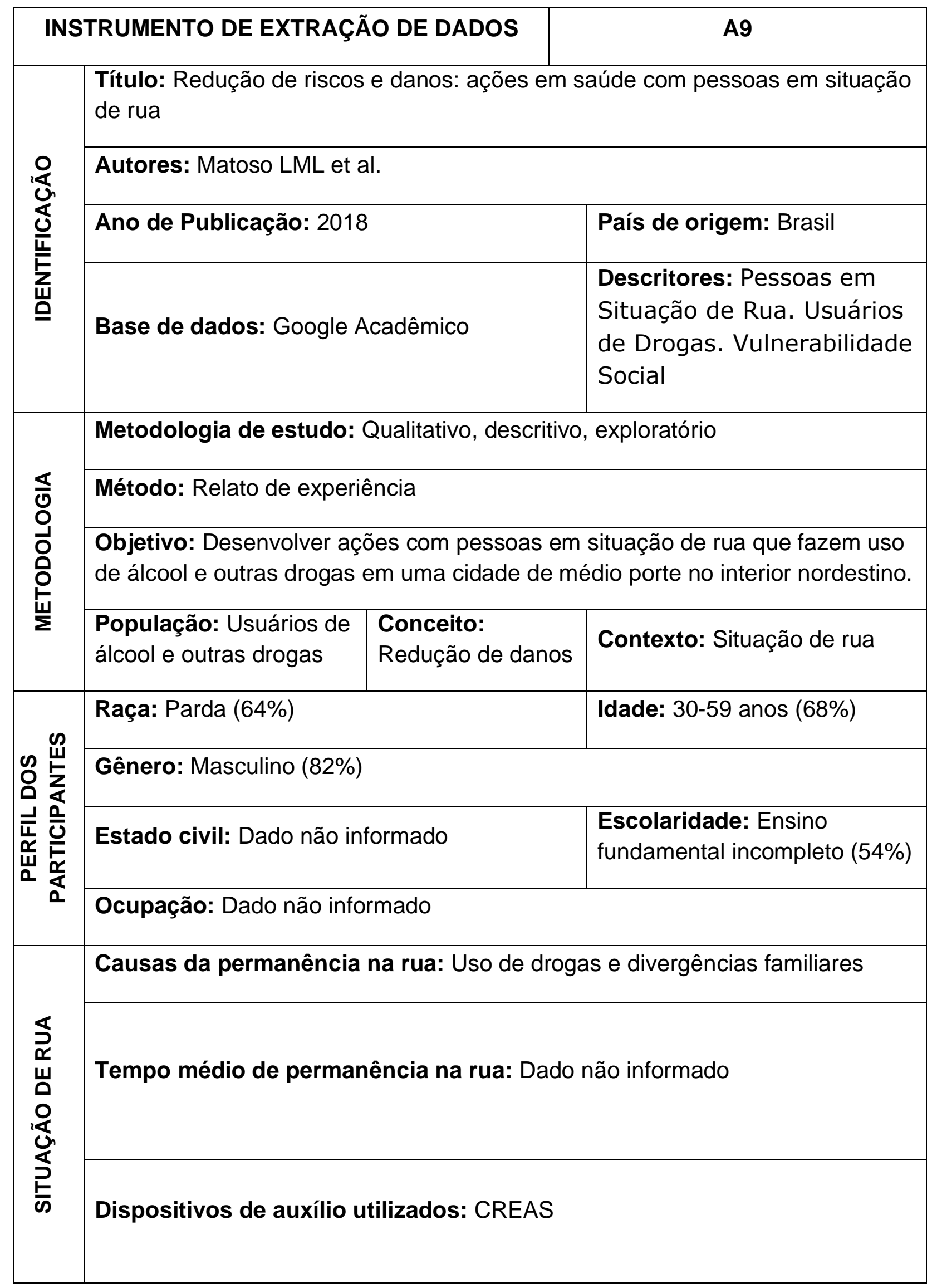




\begin{tabular}{|c|c|}
\hline \multirow{3}{*}{ 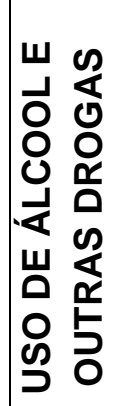 } & Drogas mais utilizadas: Álcool, maconha e crack \\
\hline & Padrão de uso médio: Dado não informado \\
\hline & Programas e dispositivos de saúde utilizados: CAPS, UPA \\
\hline \multicolumn{2}{|r|}{$\begin{array}{l}\text { Outras informações relevantes: Os autores defendem que pesquisas devem se } \\
\text { atentar a dados referentes a raça como forma de indicador sobre grau de exposição a } \\
\text { fatores sociais; }\end{array}$} \\
\hline
\end{tabular}


Apêndice C - Protocolo da revisão de escopo

Protocolo de Revisão de Escopo

\section{PERFIL DAS PESSOAS EM SITUAÇÃO DE RUA COM PROBLEMAS DE SAÚDE MENTAL DECORRENTES DO USO DE ÁLCOOL E OUTRAS DROGAS: REVISÃO DE ESCOPO}

Maria Regina Camargo Ferraz Souza ${ }^{1}$

Márcia Aparecida Ferreira de Oliveira ${ }^{1}$

1. Universidade de São Paulo

Autor correspondente:

Maria Regina Camargo Ferraz Souza

mrcferraz @usp.br

\section{Objetivo}

Analisar a produção científica sobre o perfil das pessoas em situação de rua com problemas de saúde mental decorrentes do uso de álcool e outras drogas.

\section{Introdução}

Frequentemente, o uso de álcool e outras drogas estão presentes no cotidiano de quem mora na rua como forma de suportar a situação, seja a fim de minimizar a fome e o frio, ou como uma forma de socialização entre os membros dos grupos. Ora ela se apresenta como um dos motivos primordiais da permanência da situação de rua; ora como consequência do ingresso no mundo da rua ${ }^{1}$.

Tanto a situação de rua quando o uso de álcool e outras drogas por si estigmatiza e coloca pessoas que se encontram nestes grupos às margens da população. Por sua vez, estas condições associadas aumentam a dificuldade destas pessoas no acesso a serviços básicos, comuns ao restante da população.

Nos últimos anos tem se notado um crescimento massivo da população usuária de álcool e outras drogas em situação de rua. 
A exemplo disso, no município de São Paulo - o mais populoso do país, com 12,18 milhões de habitantes ${ }^{2}$ - a concentração de usuários de drogas, majoritariamente no centro da cidade (em especial, região conhecida como Cracolândia) tem aumentado em proporções significativas.

Segundo levantamento da Secretaria Estadual de Desenvolvimento Social, entre abril de 2016 e maio de 2017 houve aumento de $160 \%$ do fluxo de usuários de álcool e outras drogas na região da cracolândia ${ }^{3}$.

Tal ação ganhou destaque na mídia, trazendo a debate novamente a estigmatização e a efetividade de políticas públicas voltadas a esta população.

Diante da problemática apresentada, se faz necessário entender quem são essas pessoas em situação de vulnerabilidade. É preciso conhecer o perfil desta população para que as ações de saúde cheguem até ela, além de auxiliar na formulação de políticas públicas efetivas dentro deste grupo.

O cuidado dos usuários de álcool e drogas no Brasil caminha junto com as mudanças instituídas no país a partir da Lei 10.2016/20014, uma vez que primeiras políticas públicas voltadas ao tratamento do uso abusivo de álcool e outras drogas começaram a ser discutidas e implementadas no início dos anos 2000.

Em 2002, o Ministério da Saúde, por meio da Portaria no 816, criou o Programa Nacional de Atenção Integral a Usuários de Álcool e Outras Drogas.

Entre outras disposições, - como a articulação em rede e para a organização de fluxos assistenciais nas três esferas de governo - a portaria em questão previa a criação dos primeiros Centros de Atenção Psicossocial - Álcool e Drogas (CAPS AD).

No mesmo ano, o Governo do Estado de São Paulo o instituiu o decreto no 46.860/2002, criando assim o Centro de Referência de Álcool, Tabaco e Outras Drogas - CRATOD, que posteriormente, através da Portaria 2.103/GM, foi habilitado entre os primeiros CAPS-AD do país ${ }^{5}$. 
A criação e implantação do CRATOD foi um processo transformador na assistência ao tratamento de álcool e outras drogas oferecido pelo Estado, pois possibilitou o oferecimento de um serviço alinhado com as propostas da Reforma Psiquiátrica e mais acessível à sua população alvo, que até então era estigmatizada e excluída.

Em 2012, dez anos após sua criação, o CRATOD foi reformulado e a partir da Portaria no 130/2012, do Ministério da Saúde, o serviço passa a ser classificado como o CAPSAD III Qualificado e com o decreto estadual no 57.775/2012, passa a ter funcionamento ininterrupto. ${ }^{5}$

Assim, em 2013, houve um novo aporte de recursos financeiros e humanos para a Instituição. Esse aporte permitiu então o desenvolvimento de ações de cuidado mais próximas do território e dos usuários da famigerada cracolândia.

Visando assim aperfeiçoamento e integração de suas ações de manejo da dependência química, através do decreto no 59.684/2013, foi instituído o Programa Estadual de Enfrentamento ao Crack - Programa Recomeço, que, vinculado ao CRATOD, tem por objetivo atender usuários de substâncias psicoativas especialmente o crack, e seus familiares ${ }^{6}$.

Em 2015, houve reestruturação do Programa Recomeço (Decreto no 61.664/2015) ${ }^{7}$, que passou a se denominar Programa Estadual de Políticas sobre Drogas - Programa Recomeço: uma vida sem drogas.

O Programa também passou a contar com a atuação coordenada das Secretarias da Educação, Saúde, Desenvolvimento Social, Segurança Pública e Justiça.

Até 2018, o serviço chegou a oferecer mais de 2.500 internações e 1.500 acolhimentos em comunidades terapêuticas. Dentro do seu CAPS-AD III (Centro de Atenção Psicossocial - Álcool e Drogas), realiza mais de 2.000 oficinas, que atendem 25.000 pessoas, além de projetos terapêuticos singulares e serviços odontológicos para mais de 1.300 pacientes, todos os anos. ${ }^{5}$ 
Mesmo com a implementação de serviços e ações como o CRATOD e Recomeço, dos Governos Estadual e Municipal de São Paulo, o acesso da população de rua ainda é algo que necessita ser ampliado.

Tendo em vista as dificuldades da população de rua que faz uso de álcool e outras drogas ao acesso a serviços essenciais, dentre outros problemas, 0 presente estudo busca responder, com base na literatura quem são estas pessoas e quais características definidoras trazem consigo.

\section{Pergunta de Revisão}

Qual é o perfil das pessoas em situação de rua com problemas de saúde mental decorrentes do uso de álcool e outras drogas?

\section{Palavras-chave}

- Português: Pessoas em Situação de Rua; Usuários de Drogas; Drogas Ilícitas;

- Inglês: Homeless persons; Drug Users; Street Drugs;

- Espanhol: Personas Sín Hogar; Consumidores de Drogas; Drogas Ilícitas;

\section{Critério de inclusão}

- Tipos de participantes: Pessoas em situação de rua com problemas de saúde mental decorrentes do uso de álcool e outras drogas

- Conceito: Uso de álcool e outras drogas

- Contexto: Situação de rua

\section{Tipos de fontes}

A fim de atender aos critérios de inclusão propostos, a presente revisão de escopo considerará estudos do tipo qualitativos, quantitativo e misto (quanti e qualitativos) com diferentes metodologias: descritiva e exploratória, abordagem etnográfica, ensaio clínico controlado com randomização, amostra de conveniências, assim como revisões sistemáticas que busquem explanar características 
sociodemográficas e de saúde presentes no perfil de pessoas em situação de rua com doença mental decorrente do uso de álcool e outras drogas.

\section{Estratégia de pesquisa}

A busca de estudos será realizada nas bases PUBMED, LILACS/BVS e Google Acadêmico, uma vez que, o Manual do Joanna Briggs Institute - $\mathrm{JBI}^{8}$ indica a utilização de pelo menos dois bancos de dados online relevantes para o tópico.

As bases de dados utilizadas no presente estudo foram escolhidas com base nas recomendações dos manuais de pesquisa de escopo ${ }^{8}$. Desta forma, destaca-se que a PUBMED compreende um vasto acervo com grande impacto internacional, enquanto a LILACS/BVS é elementar tratando-se de literatura nacional e latinoamericana. Optou-se pelo Google Acadêmico como plataforma adjuvante na busca de material nacional.

A fim de refinar as buscas e encontrar referencias que contemplem todos os termos pesquisados, os booleano AND e OR serão empregados, quando necessário.

No PUBMED serão utilizados os seguintes MeSH terms (Medical Subject Terms), em inglês: "Drug Users" OR "Drug Abusers", AND "Illicit Drugs" OR "Street Drugs" AND "Homelessness" OR "Homeless Persons" OR "Homeless People".

No portal LILACS/BVS, a busca por título, resumo e assunto. Se dará a patir dos seguintes descritores: em português "Usuários de Drogas" AND "Drogas llícitas" AND "Pessoas em Situação de Rua"; em espanhol "Consumidores de Drogas" AND "Drogas Ilícitas" AND "Personas Sín Hogar"; e em inglês, "Drug Users" AND "Street Drugs" OR “Illicit Drugs” AND "Homeless Persons”.

Serão excluídos da presente revisão os estudos repetidos em diferentes bases de dados.

A captação de estudos nas bases de dados terá início em outubro de 2019 e se estenderá até saturação do tema.

Os seguintes critérios de inclusão serão seguidos:

I. Período: A pesquisa foi limitada a estudos publicados a partir de 2009, ano qual foi instituída a Política Nacional para a População em Situação de Rua, pelo Governo Federal; 
II. Idioma: português, inglês e espanhol;

III. Disponibilidade: Textos completos na íntegra;

IV. Temática: Uso de álcool e outras drogas na população em situação de rua;

Foram determinados como critérios de exclusão:

I. Duplicação de estudos em uma ou mais bases;

II. Estudos não disponíveis Online;

III. Estudos não disponíveis na integra;

IV. Estudos sobre a população em situação de rua com foco em doença mental não relacionada ao uso de álcool e outras drogas e/ou doenças crônicas

V. Estudos com foco em infecções sexualmente transmissíveis (ISTs) em pessoas em situação de rua que apresentem ou não doença mental relacionada ao uso de álcool e outras drogas;

VI. Estudos que discorram sobre população em situação de rua e encarceramento;

VII.Estudos limitados a gênero;

VIII. Estudos limitados a faixa etária;

IX. Estudos em que o público alvo foram familiares dos usuários de pessoas com doenças mentais decorrentes do uso de álcool e drogas em situação de rua;

$X$. Estudos em que a pessoa com doenças mentais decorrentes do uso de álcool e outras drogas em situação de rua encontrese internado (hospital, comunidades terapêuticas, casas de repouso e outros.) 


\section{Extração dos dados}

Após escolha de estudos e análise dos mesmos através da avaliação de dois revisores, os dados pertinentes a pergunta norteadora proposta pela dissertação em questão serão extraídos por meio de um instrumento de extração de dados.

Ressalta-se que nas situações em que os revisores não entrarem em acordo, será solicitada a avaliação do estudo por um terceiro revisor, vinculado ao GEAD Grupo de estudos de álcool e drogas.

Ainda acerca do instrumento, destacamos que este do desenvolvido especificamente para esta revisão de escopo (Apêndice A), no qual permitirá a extração dos dados relevantes.

\section{Apresentação dos resultados}

Os resultados serão apresentados através da elaboração de uma síntese sobre produção de conhecimentos sobre o perfil das pessoas em situação de rua com problemas de saúde mental decorrentes do uso de álcool e outras drogas.

Os principais conceitos apresentados pelos estudos referentes ao perfil das pessoas em situação de rua com problemas de saúde mental decorrentes do uso de álcool e outras drogas serão mapeados de modo a facilitar a caracterização da população alvo.

\section{Conflitos de interesse}

Declaro que não há conflitos de interesse.

\section{Referências}

1 Spadoni L, Machado Júnior CP, Silva Neto C, Carvalho J, Gonçalves C. O medo e a polidrogadição em moradores de rua usuários de crack. Atas: Inv. Qual. em Ed. [Internet] 2014 [Acesso em: 02 nov. 2017]; Disponível em: http://www.proceedings.ciaiq.org/index.php/CIAIQ/article/view/506/501 
2 IBGE - Instituto Brasileiro de Geografia e Estatística. População estimada: IBGE, Diretoria de Pesquisas, Coordenação de População e Indicadores Sociais, Estimativas da população residente com data de referência 10 de julho de 2019. [Internet] 2020 [Acesso em: 15 jan. 2020]; Disponível em: https://cidades.ibge.gov.br/brasil/sp/sao-paulo/panorama

3 Leite F. Pesquisa revela que população da Cracolândia cresceu $160 \%$ em um ano. O Estado de S. Paulo. [Internet]. 2017 jun. 08 [citado em 2017 nov. 03]. Disponível em: http://sao-paulo.estadao.com.br/noticias/geral,pesquisarevela-que-populacao-da-cracolandia-cresceu-160-em-um-ano,70001832252

4 Brasil. Ministério da Saúde. Portaria no 816, de 30 de abril de 2002. Institui, no âmbito do Sistema Único de Saúde, o Programa Nacional de Atenção Comunitária Integrada a Usuários de Álcool e Outras Drogas, a ser desenvolvido de forma articulada pelo Ministério da Saúde e pelas Secretarias de Saúde dos estados, Distrito Federal e municípios. In Diário Oficial da União.[Internet]. 2020 out. 15. Disponivel em: http://bvsms.saude.gov.br/bvs/saudelegis/g

5 Zoldan LGV, Ribeiro M. O CRATOD e o tratamento da dependência química no Brasil. In: Zoldan LGV, Ribeiro M. editor. CRATOD 15 ANOS - Uma proposta de cuidado ao dependente químico. [Internet]. 1a ed. São Paulo: Governo do Estado de São Paulo, 2017. 374 p. [citado em 02 mar 2019] Disponível

em:

http://www.saude.sp.gov.br/resources/cratod/download/cratod_15_anos.pdf

6 São Paulo (Estado). Decreto n. 59.684/2013, de 31 de outubro de 2013. Dá nova redação e acrescenta dispositivo ao Decreto ํo 59.164 , de 2013, que institui o Programa Estadual de Enfrentamento ao Crack, denominado Programa Recomeço, e dá providências correlatas. Diário Oficial do Estado de São Paulo. 2013; 123 (206):1.

7 São Paulo (Estado). Decreto n. 61.664, de 02 de dezembro de 2015. Reorganiza o "Programa Estadual de Enfrentamento ao Crack - Programa Recomeço", que passa a denominar-se "Programa Estadual de Políticas sobre Drogas - Programa Recomeço: uma vida sem drogas. Diário Oficial do Estado de São Paulo. 2015;224(125):1. 
8 Peters MDJ, Godfrey C, Mclnerney P, Baldini Soares C, Khalil H, Parker D. Capítulo 11: Avaliações de escopo. Em: Aromataris E, Munn Z (Editores). Manual do Revisor do Instituto Joanna Briggs. Instituto Joanna Briggs, 2017. Disponível em https://reviewersmanual.joannabriggs.org/ 